\title{
Entonación de enunciados declarativos en el español hablado en Querétaro: una comparación entre hablantes bilingües y monolingües
}

Eva Patricia Velásquez Upegui

Velásquez Upegui, E. P. (2021). Entonación de enunciados declarativos en el español hablado en Querétaro: una comparación entre hablantes bilingües y monolingües. Revista de Filología y Lingüística de la Universidad de Costa Rica, 47(2), e46756. doi: https://doi.org/10.15517/rfl.v47i2.46756

\section{(9) $\mathbb{P Q \Theta}$}

Doi: https://doi.org/10.15517/rfl.v47i2.46756

URL: https://revistas.ucr.ac.cr/index.php/filyling/index 
Revista de Filología y Lingüística de la Universidad de Costa Rica

ISSN: 0377-628X

ISSN: 2215-2628

filyling@gmail.com

Universidad de Costa Rica

Costa Rica

\title{
Entonación de enunciados declarativos en el español hablado en Querétaro: una comparación entre hablantes bilingües y monolingües
}

\author{
Velásquez Upegui, Eva Patricia \\ Entonación de enunciados declarativos en el español hablado en Querétaro: una comparación entre hablantes \\ bilingües y monolingües \\ Revista de Filología y Lingüística de la Universidad de Costa Rica, vol. 47, núm. 2, e46756, 2021 \\ Universidad de Costa Rica, Costa Rica \\ Disponible en: https://www.redalyc.org/articulo.oa?id=33266553012 \\ DOI: https://doi.org/10.15517/rfl.v47i2.46756
}

\section{(c) (1) $\Theta$}

Esta obra está bajo una Licencia Creative Commons Atribución-NoComercial-SinDerivar 3.0 Internacional. 


\title{
Entonación de enunciados declarativos en el español hablado en Querétaro: una comparación entre hablantes bilingües y monolingües
}

\author{
Intonation of Declarative Statements in Spanish Spoken in Queretaro: Comparison Between Monolingual and \\ Bilingual Speakers
}

Eva Patricia Velásquez Upegui

Universidad Autónoma de Querétaro, Querétaro, México

evapvelasquez@uaq.edu.mx

DOI: https://doi.org/10.15517/rfl.v47i2.46756

Redalyc: https://www.redalyc.org/articulo.oa?

(iD https://orcid.org/0000-0001-6779-7331

Recepción: 06 Diciembre 2020

Aprobación: 09 Marzo 2021

\section{RESUMEN:}

El estudio de la entonación de una variedad dialectal debe contemplar las características de los diferentes hablantes que la conforman, por esta razón, en este documento se describen los enunciados declarativos en la variedad del español en el estado de Querétaro (México), a partir de la comparación entre hablantes bilingües otomí-español y monolingües español. Se consideraron 15 participantes mujeres; cinco monolingües de Santiago de Querétaro (capital), cinco monolingües del Municipio de Amealco de Bonfil, y cinco bilingües de la localidad del Bothé, en este mismo municipio. El análisis se establece siguiendo los parámetros del Modelo Métrico Autosegmental, y en correspondencia, se integran las convenciones de etiquetaje propuestas en el sistema $S p$ ToBI, desde una perspectiva cualitativa y cuantitativa. Los resultados indican que el tonema declarativo en esta variedad podría representarse como $\mathrm{L}+(\mathrm{i}) \mathrm{H}^{*} \mathrm{M} \%$, con variaciones fonéticas propias que permiten diferenciar a cada grupo de hablantes.

Palabras ClaVE: entonación, enunciados declarativos, Querétaro, bilingües, monolingües.

\section{ABstract:}

The study of intonation for a dialectal variation must consider the traits of the different speakers that comprise it. For this matter, this paper describes the declarative statements used in the variation of Spanish spoken in the state of Queretaro (Mexico), based on the comparison between Otomi-Spanish bilingual and Spanish monolingual speakers. The assessed participants were fifteen women; five of them were monolingual, from Santiago de Queretaro (state capital); five of them were monolingual, from the municipality of Amealco de Bonfil; and five of them were bilingual, from the town of El Bothé, located in the same municipality. The analysis is performed following the parameters of the Autosegmental-Metrical Model. Accordingly, the proposed labeling conventions are integrated into the Spanish ToBI system. The data is analyzed from a qualitative and quantitative standpoint. Results show that the declarative toneme in this variation could be represented as $\mathrm{L}+(\mathrm{i}) \mathrm{H}^{*} \mathrm{M} \%$, with individual phonetical variations that allow for the distinction of each group of speakers.

KEYWORDS: intonation, declarative statements, Queretaro, bilingual, monolingual.

\section{INTRODUCCIÓN}

El objetivo en este documento es describir y comparar la entonación de enunciados declarativos en diferentes variedades del español hablado en el estado de Querétaro (México), concretamente entre hablantes bilingües otomí-español de la localidad del Bothé, monolingües de Amealco, cabecera de la población del municipio de Amealco del Bonfil, y monolingües de la ciudad capital del estado, Santiago de Querétaro (Figura 1). Se pretende establecer si estas variedades comparten características prosódicas o si, por el contrario, los patrones entonativos son diferentes en cada variedad. De modo que este estudio permite no solo reconocer las características prosódicas del español queretano, sino también las diferencias entre los patrones entonativos asociados a este tipo de enunciados en hablantes bilingües y monolingües del mismo estado.

Querétaro es un estado que se localiza en el centro de México y limita con los estados de San Luis Potosí, Guanajuato, México e Hidalgo. Está conformado por 18 municipios y constituye lo que se conoce como el 
Bajío Mexicano, que se trata de una región geográfica y cultural ubicada en la zona central del país. De acuerdo con el Censo de Población y Vivienda (INEGI, 2015), en el estado de Querétaro el $40 \%$ o más de la población mayor de 3 años habla alguna lengua indígena y no habla español. Por tanto, la situación de bilingüismo es común en los diferentes municipios queretanos, principalmente en Tolimán, Amealco de Bonfil y Querétaro (CDI-PNUD, 2009).

Por su parte, Amealco de Bonfil, ubicado al sur del estado de Querétaro, es uno de los municipios que cuenta con el mayor número de hablantes de lenguas originarias. Este municipio está subdividido en cuatro microrregiones, una de las cuales corresponde a San Ildefonso Tultepec, donde se encuentra la comunidad del Bothé (Figura 1). En esta región de Amealco, se preserva la lengua otomí como parte de la identidad social, sin embargo, en la mayoría de ocasiones, se deja de lado por cuestiones funcionales asociadas con el trabajo, el comercio, la salud y la educación. Las personas de mayor edad utilizan la lengua en casa y entre vecinos, y aunque intentan preservarla con las generaciones más jóvenes, en algunos casos no prospera dado que no es la lengua de prestigio ${ }^{1}$. En esta localidad, se elabora en mayor medida la artesanía para uso propio y para fines comerciales (Figueria, 2001).

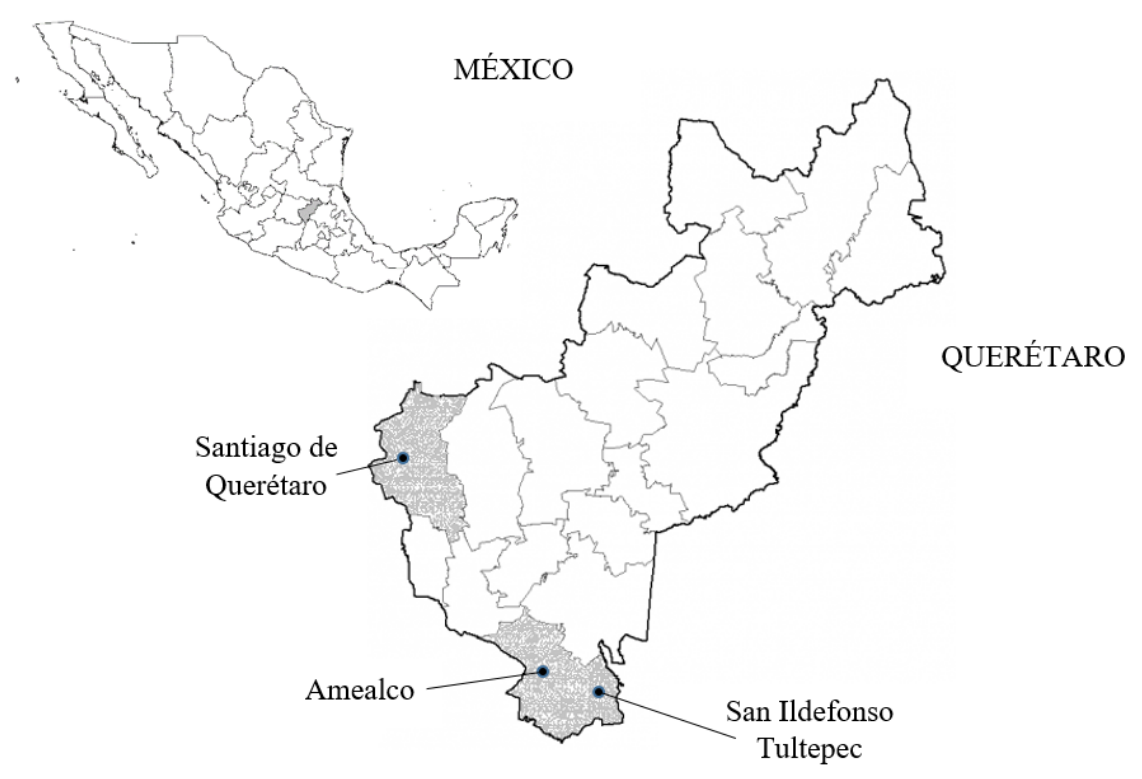

FIGURA 1.

Ubicación de San Ildefonso Tultepec, Amealco y Santiago de Querétaro

A pesar de que el estudio prosódico en México ha dado lugar a diversas descripciones (Coronado Hernández, 2014; De-la-Mota, Martín Butragueño y Prieto, 2010; Gil Burgoin, 2011, 2017; MartínButragueño, 2004, 2006a, 2006b, 2011, 2019; Mendoza Vázquez, 2014, 2019; Orozco, 2016; Radillo Enríquez, 2011; Sagastuy y Fernández Planas, 2014), aún no se incluye un estudio de la entonación del español queretano ${ }^{2}$. De modo que este trabajo se integra a la construcción del panorama geoprosódico del español mexicano y, de igual manera, a la descripción de la entonación en las comunidades de habla del estado de Querétaro. En adelante, se presenta una breve revisión de estudios previos con respecto a la entonación del español en contacto con diferentes variedades regionales; posteriormente, se expone la metodología llevada a cabo, seguida por los resultados de este estudio y, por último, las conclusiones. 


\section{ANTECEDENTES}

Los estudios prosódicos sobre el contacto de lenguas han tenido un amplio desarrollo en los últimos años. Este avance ha ido de la mano con los estudios sobre contacto de dialectos, entendiendo, en este caso, las diferentes variedades de una misma lengua determinadas diatópicamente. Con relación a la entonación de las diferentes variedades del español en contacto, Cuevas y López-Bobo (2011) comparan los dialectos oriental y occidental del español de Cantabria, y dan cuenta de un contínuum prosódico que parte de patrones más tradicionales y se van modificando tanto en áreas rurales como urbanas (Cuevas Alonso y Miguel Álvarez, 2019).

López-Bobo y Cuevas-Alonso (2009) obtienen resultados similares en la revisión de la variedad oriental del español cántabro a partir de la variedad rural y urbana en Laredo. Los resultados corroboran la existencia de un contínuum prosódico en la zona noroccidental de la Península sin fronteras dialectales nítidas.

Elejabeitia, Iribar, y Pagola (2008) comparan tres variedades dialectales del español en el área de contacto euskera-español (Donostia, Bilbao y Vitoria-Gasteiz). Los autores encuentran coincidencias en el patrón entonativo de los enunciados declarativos mientras que en las interrogativas se presentaron dos patrones: con final ascendente, común en Donostia y Bilbao, y final descendente, para la ciudad de Vitoria-Gasteiz.

Alvarellos, Muñiz-Cachón, Díaz, y González (2011) estudian la entonación de enunciados declarativos e interrogativos de Asturias. Para los autores la prosodia asturiana puede describirse como un contínuum entre la melodía gallega y la cántabra que resulta mucho más evidenciable en los contornos de enunciados interrogativos.

Van Oosterzee et al. (2007) comparan la producción y la percepción de enunciados interrogativos sin expansión en las variedades españolas de Tortosí y Lleidatà, a partir del análisis de F0, duración e intensidad. Los autores señalan claras diferencias entre los tipos de interrogativas, al igual que en los dos dialectos estudiados. Por su parte, Romera, Salcioli, Fernández-Planas, Carrera, y Román (2008) estudian el español en contacto con el catalán, los autores explican que existe una fuerte influencia de la prosodia en contacto con la lengua materna.

Martín-Butragueño (2014) estudia el contacto de dialectos en procesos de migración interna en la Ciudad de México, a partir del análisis de la sílaba nuclear y las junturas terminales. El autor encuentra que es posible reconocer tres identidades vernáculas asociadas i) al origen de los migrantes, ii) a la Ciudad de México, y iii) a la solidaridad de grupo evidenciada en situaciones conversacionales. Martín-Butragueño (2016), con hablantes de Ecatepec, Estado de México, señala que el aumento de la duración en el tonema se relaciona con la aparición de junturas complejas que están asociadas con funciones discursivas y de solidaridad social y desarrollo de identidades.

Gabriel y Kireva (2014) estudian la prosodia en hablantes de español porteño, de italiano y de aprendientes de italiano con el español como L1 y encuentran similitudes entre el español porteño y el italiano que permiten hablar de una transferencia prosódica durante el proceso de adquisición del español por migrantes italianos. En este estudio, el ritmo arrojó resultados más conclusivos con respecto a la transferencia prosódica, posteriormente, Kireva y Gabriel (2015) estudian el ritmo en hablantes del español porteño, del español como L2, monolingües del español de Castilla e italiano, y corroboran la hipótesis de la transferencia.

Kireva y Gabriel (2016) comparan la entonación y la duración entre el español hablado en Olivenza, el portugués de esta misma ciudad y el español hablado en Castilla. Los autores encuentran similitudes entre las variedades de Olivenza y diferencias en relación con el español de Castilla, estos resultados indican que la variedad del español de Olivenza evidencia un proceso de transferencia y acomodación prosódica.

Por su parte, Congosto (2019) describe la entonación del español mexicano en dos grupos de hablantes con el objetivos de conocer los efectos prosódicos derivados de situaciones de contacto (Congosto Martín y Morgenthaler, 2019). Un grupo está conformado por tres mujeres migrantes con diferentes situaciones sociolingüísticas quienes residen en Los Ángeles, y el otro grupo, corresponde a dos mujeres que residen 
en México. Se analizan enunciados declarativos e interrogativos absolutos colectados de acuerdo con la metodología del proyecto AMPER (Martínez Celdrán y Fernández Planas, 2003-2020). La autora no encuentra rasgos prosódicos que permitan diferenciar ambas modalidades oracionales en los dos grupos de informantes por lo que explica que se trata de una misma comunidad de habla que se extiende más allá de las fronteras políticas.

En línea con el estudio anterior, Congosto (2020) estudia los rasgos prosódicos que caracterizan el español de migrantes hispanos que residen en Los Ángeles, principalmente, en mujeres migrantes guatemaltecas. La autora compara sus hallazgos con hablantes del mismo sexo residentes de la Ciudad de Guatemala, con base en los datos recopilados en el trabajo de Utgård (2014). Los resultados encontrados revelan que hay diferencias entre ambos grupos de hablantes, tales diferencias se observan en los enunciados declarativos que, en el caso de las hablantes migrantes, presentan un pico inicial seguido de una caída continua del tono hasta el final del enunciado, mientras que las residentes en Ciudad de Guatemala presentan tres movimientos tonales en correlación con la estructura acentual del enunciado. Los enunciados interrogativos no evidenciaron diferencias entre las hablantes migrantes y las que permanecen en la Ciudad de Guatemala.

Estas investigaciones revelan que al estudiar una variedad a nivel entonativo se deben reconocer los procesos internos de contacto de dialectos que en muchos casos explican la diversidad dialectal, y de igual manera, permiten construir una descripción más precisa de las características prosódicas de una comunidad de habla. En este sentido, los procesos de contacto que afectan a la estructura prosódica no se refieren de manera exclusiva al contacto entre lenguas sino también al contacto de dialectos, un tema que aún sigue en exploración.

\subsection{Enunciados declarativos en el español de México}

Las descripciones sobre los enunciados declarativos en el español de México han tenido un aumento considerable en los últimos años y, en la mayoría de los casos, prevalece un enfoque geoprosódico (Tabla 1); sin embargo, difieren en cuanto al número y características de los informantes ${ }^{3}$, y en cuanto al tipo de datos colectados que oscila entre datos semiespontáneos (Mendoza Vázquez, 2014), y datos de mayor naturalidad (Coronado Hernández, 2014).

Entre las generalidades que tales investigaciones arrojan se encuentran básicamente tres tonos asociados a la sílaba nuclear. El tono nuclear más documentado corresponde al bitono $\mathrm{L}+(\mathrm{i}) \mathrm{H}^{*}$, es decir, un movimiento ascendente desde un inicio bajo que transcurre a lo largo de la sílaba nuclear. En la mayoría de los casos reportados, se señala un ascenso mayor a lo esperado, tal es el caso de las variedades de Ciudad de México, Tlaxcala, Michoacán, Tuxtla y Oaxaca (Tabla 1).

También se documentan los tonos $\mathrm{L}^{*}, ! \mathrm{H}^{*}, \mathrm{H}^{*}$, que corresponden a movimientos bajos, sostenidos y altos, respectivamente. Estos tonos parecen coexistir con el tono ascendente $\mathrm{L}^{+\mathrm{H}^{*}}$, este es el caso de Ciudad de México, Baja California Sur, Monterrey y Tuxtla. En la ciudad de Guadalajara, solo se han reportado tonos descendentes y sostenidos a diferencia de las demás variedades descritas (Tabla 1).

Con relación a las junturas terminales, comúnmente se han referido finales descendentes L\%, para la Ciudad de México, Tlaxcala, Tuxtla y Oaxaca. Además, se han encontrado tonos sostenidos M\%, reportados en Guadalajara, Michoacán y Monterrey. En algunos casos, se han documentado junturas complejas del tipo HM\%, HL\% y LM\%, como en Michoacán, Baja California Sur y Monterrey (Tabla 1). 
TABLA 1.

Tonema de enunciados declarativos en diferentes variedades del español en México

\begin{tabular}{|c|c|c|c|}
\hline Zona & $\begin{array}{l}\text { Acento } \\
\text { nuclear }\end{array}$ & $\begin{array}{l}\text { Juntura } \\
\text { terminal }\end{array}$ & Autor \\
\hline Ciudad de México ${ }^{4}$ & $\begin{array}{l}\mathrm{L}^{*} \\
\mathrm{~L}+{ }_{i} \mathrm{H}^{*} \\
\mathrm{LH}\end{array}$ & $\begin{array}{l}L \% \\
L \% \\
L \%\end{array}$ & $\begin{array}{l}\text { De la Mota et al. (2010) } \\
\text { Martín Butragueño (2004, 2006a, 2006b) } \\
\text { Martín Butragueño (2011) }\end{array}$ \\
\hline Cuapiaxtla/Tlaxcala & $\mathrm{L}+(\mathrm{i}) \mathrm{H}^{*}$ & $\mathrm{~L} \%$ & Mendoza Vázquez (2014) \\
\hline Tlachco/Tlaxcala & $\mathrm{L}+{ }_{j} \mathrm{H}^{*}$ & $\mathrm{~L} \%$ & Coronado Hernández (2014) \\
\hline Michoacán & $\mathrm{L}+{ }_{i} \mathrm{H}^{*}$ & $\begin{array}{l}\mathrm{L} \%, \mathrm{M} \%, \\
\mathrm{LM} \%\end{array}$ & Coronado Hernández (2014) \\
\hline Baja California Sur & $\begin{array}{l}\mathrm{L}+\mathrm{H}^{*}, \mathrm{H}^{*} \\
\mathrm{~L}+\mathrm{H}^{*}\end{array}$ & $\begin{array}{l}\mathrm{L} \%, \mathrm{HL} \% \\
\mathrm{HM} \%\end{array}$ & $\begin{array}{l}\text { Gil Burgoin (2011) } \\
\text { Gil Burgoin (2017) }\end{array}$ \\
\hline Guadalajara & $\begin{array}{l}\mathrm{L}^{*}, \mathrm{H}+\mathrm{L}^{*} \\
! \mathrm{H}^{*} \\
\mathrm{~L}^{*}\end{array}$ & $\begin{array}{l}\mathrm{L} \%, \mathrm{M} \% \\
\mathrm{~L} \%, \mathrm{M} \% \\
\mathrm{M} \%\end{array}$ & $\begin{array}{l}\text { Orozco (2016) } \\
\text { Radillo Enríquez (2011) } \\
\text { Gil Burgoin (2017) }\end{array}$ \\
\hline Monterrey & $\begin{array}{l}! \mathrm{H}^{*} \\
\mathrm{~L}+\mathrm{H}^{*}\end{array}$ & $\begin{array}{l}\mathrm{M} \% \\
\mathrm{HM} \%\end{array}$ & $\begin{array}{l}\text { Montellano Moreno (2017) } \\
\text { Gil Burgoin (2017) }\end{array}$ \\
\hline
\end{tabular}

Estos datos generales derivados de las diferentes investigaciones realizadas (Tabla 1) parecen corroborar la preferencia por una realización circunfleja asociada al tonema de los enunciados declarativos en la variedad del español mexicano representado como $\mathrm{L}+\mathrm{H}^{*}$. Además, los tonos de juntura terminal documentados son típicamente descendentes L\% y sostenidos M\%. De modo que, resulta pertinente reconocer si la configuración del enunciado declarativo en la variedad del español queretano coincide con las configuraciones hasta ahora descritas de tal manera que contribuya con el panorama geoprosódico del español mexicano. En la Figura 2 se representa el inventario de tonos más frecuentes reportados en las investigaciones referidas (Tabla 1 ): 


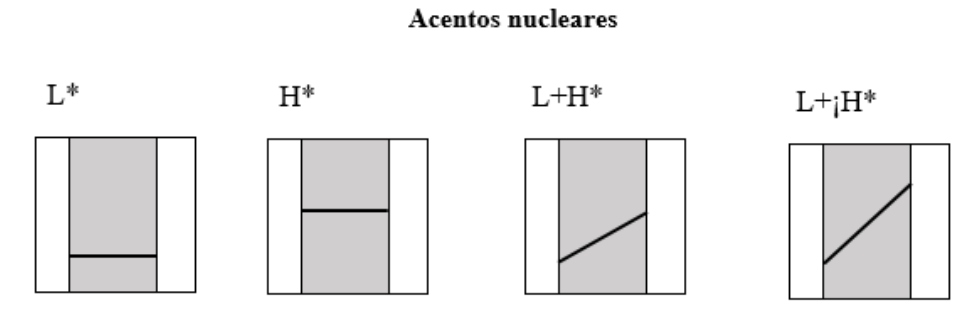

Tonos de juntura terminal

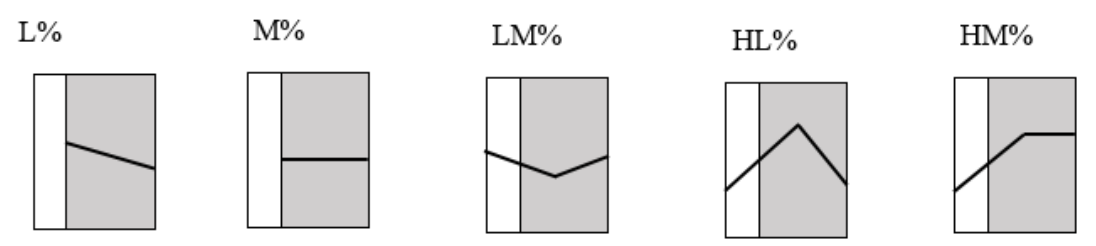

FIGURA 2.

Acentos nucleares y junturas terminales más frecuentes reportadas en el español de México (Tabla 1)

\section{Metodología}

\subsection{Participantes}

El conjunto de hablantes corresponde a 15 mujeres en total (Tabla 2), y está divido en tres grupos de cinco hablantes. El primer grupo está conformado por hablantes bilingües (HB) de San Ildefonso Tultepec (localidad el Bothé), todas las hablantes cuentan con el otomí como lengua materna ${ }^{5}$. Las participantes se encuentran en un rango de edad de 45 a 66 años, todas ellas con nivel de instrucción bajo (primaria) alcanzado en escuelas monolingües en español ${ }^{6}$. En general, se dedican a las labores del hogar, a la elaboración de artesanías y a empleos eventuales en la ciudad de Santiago de Querétaro.

El segundo grupo lo integran hablantes monolingües del español, oriundas del municipio de Amealco (cabecera municipal) (HMA). Este grupo de mujeres se encuentra en un rango de edad entre los 45 y 55 años. Con relación al nivel de estudios, en general, es bajo, correspondiente a estudios de básica primaria y, en algunos casos, secundaria inconclusa. Su principal ocupación es el hogar. Esta actividad se alterna con labores en el campo o en tiendas caseras.

En el tercer grupo, se encuentran hablantes monolingües de español, originarias de la ciudad de Santiago de Querétaro (capital el estado de Querétaro) (HMQ), con edades entre los 42 y 52 años. El nivel de estudios al que pertenecen las informantes es secundaria y preparatoria trunca o terminada, y sus principales ocupaciones son el hogar y oficios varios.

Para determinar el grado de dominancia de lenguas de las participantes bilingües de San Ildefonso Tultepec, se empleó el cuestionario Bilingual Language Profile (BLP). Los resultados que arroja este cuestionario ofrecen una valoración cuantitativa del perfil lingüístico a partir de la medición de su historial lingüístico, el uso de las lenguas y las actitudes lingüísticas (Birdsong, Gertken y Amengual, 2012). De acuerdo con la información proporcionada por el BLP, en tres de las hablantes bilingües, el español presentó mayor dominancia en relación con el otomí, mientras que las dos hablantes restantes presentaron mayor dominancia del otomí. 
TABLA 2.

Información de las participantes

\begin{tabular}{|c|c|c|c|c|}
\hline \multicolumn{2}{|c|}{ Hablantes } & \multirow{2}{*}{$\begin{array}{c}\text { Edad } \\
66\end{array}$} & \multirow{2}{*}{$\begin{array}{l}\text { Nivel de instrucción } \\
\text { Primaria }\end{array}$} & \multirow{2}{*}{$\begin{array}{c}\text { Ocupación } \\
\text { Ama de casa-Artesana }\end{array}$} \\
\hline Hablantes & HB1 & & & \\
\hline & HB2 & 46 & Primaria & Ama de casa \\
\hline & HB3 & 45 & Primaria & Ama de casa \\
\hline & HB4 & 45 & Primaria & Ama de casa \\
\hline & $\mathrm{HB} 5$ & 46 & Primaria & Ama de casa-Oficios varios \\
\hline \multirow{5}{*}{$\begin{array}{l}\text { Hablantes } \\
\text { Monolingües } \\
\text { Amealco HMA }\end{array}$} & HMA1 & 45 & Primaria & Ama de casa \\
\hline & HMA2 & 45 & Primario & Ama de casa \\
\hline & HMA3 & 45 & Secundaria inconclusa & Ama de casa \\
\hline & HMA4 & 54 & Primaria & Ama de casa-Campo \\
\hline & HMA5 & 55 & Secundaria inconclusa & Ama de casa-Tienda \\
\hline \multirow{5}{*}{$\begin{array}{l}\text { Hablantes } \\
\text { Monolingües } \\
\text { Querétaro } \\
\text { HMQ }\end{array}$} & HMQ1 & 48 & Secundaria & Ama de casa \\
\hline & HMQ2 & 52 & Secundaria & Ama de casa \\
\hline & HMQ3 & 42 & Preparatoria & Ama de casa \\
\hline & HMQ4 & 46 & Secundaria & Oficios varios \\
\hline & HMQ5 & 52 & Preparatoria & Oficios varios \\
\hline
\end{tabular}

\subsection{Instrumentos}

Para reunir los enunciados declarativos se eligieron 20 imágenes fotográficas que representaban situaciones de la cotidianidad (Figura 3) ${ }^{7}$. Con el objetivo de inducir la emisión de estos enunciados, se les preguntaba a las participantes: ¿Qué ve en la imagen? Las producciones emitidas, en general, correspondían con focos amplios, presentativos o informativos (Gutiérrez Bravo, 2008), en los que ninguno de los constituyentes del enunciado presentaba énfasis, realce o distinción en particular, es decir, toda la información del enunciado se considera igualmente relevante.

Aunque se presentaron las mismas imágenes a todas las participantes, no se produjeron exactamente los mismos enunciados, es decir, no tenían la misma extensión en cuanto al número de sílabas. Entonces, ante una imagen como la de Figura 3, las hablantes expresaron enunciados como i) la niña está echando tortillas, ii) una niña haciendo tortillas o iii) la niña hace tortillas, a pesar de que, en cada caso, el contenido del enunciado en términos descriptivos es el mismo, la formalización varía en cuanto al número de sílabas y, por ende, en la cantidad de acentos tonales que conforman cada enunciado. Por esta razón, en el análisis del segmento pretonemático se clasificaron los acentos tonales de acuerdo con el lugar de aparición en el enunciado. En general, los enunciados contaron con un mínimo de un acento tonal (AT) hasta tres acentos tonales en el pretonema. Por ejemplo: a) un acento tonal: un niño corriendo; b) dos acentos tonales: un niño está comiendo, y c) tres acentos tonales: un niño pequeño está jugando.

Las grabaciones se realizaron en las casas de las participantes, quienes produjeron el enunciado en dos ocasiones. La primera emisión fue considerada como entrenamiento y solo se tuvieron en cuenta las segundas emisiones terminadas en palabra llana para mantener el mismo criterio de comparación entre los datos recopilados ${ }^{8}$. 


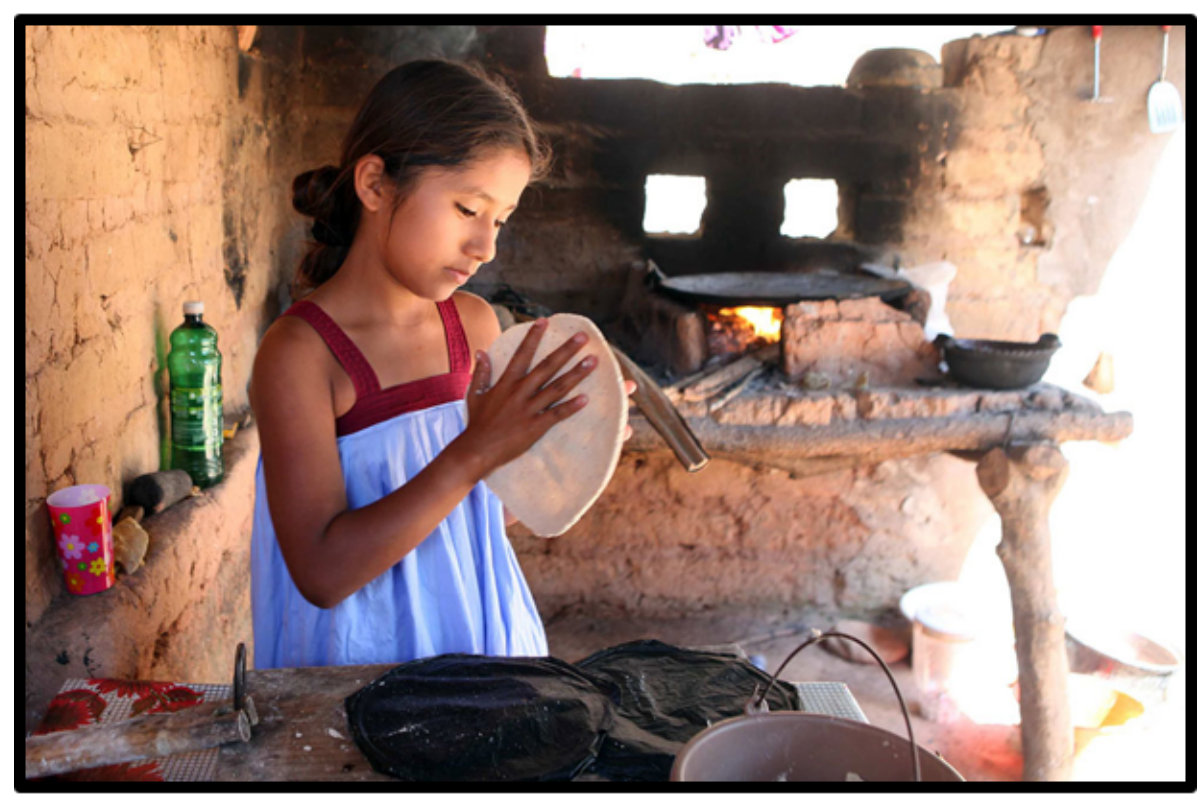

FIGURA 3.

Imagen para elicitación de datos ${ }^{9}$ (Castillo, s. f.).

\subsection{Procedimiento}

En relación con el análisis de los enunciados, se toma como base el Modelo Métrico Autosegmental (AM) (Gussenhoven, 2004; Hualde, 2003; Ladd, 1996; Pierrehumbert, 1980; Prieto, 2003), con el objetivo de determinar contrastes en el sistema entonativo. En correspondencia con el modelo, en el proceso de etiquetaje se utiliza el sistema de notación para el español $S p_{-} T o B I$ (Tones and Break Indices) (Estebas-Vilaplana y Prieto, 2008) ${ }^{10}$.

Para el análisis acústico se utilizó el software Praat versión 6.0.55 (Boersma y Weenink, 1992). Los enunciados fueron segmentados en sílabas y vocales, y en cada uno de estos puntos, se establecieron las mediciones de la F0 en semitonos (st), además se calcularon las diferencias entre un punto y otro (Figura 4). De igual manera, en cada enunciado se realizó la asignación de cesuras y la transcripción fonológica. 


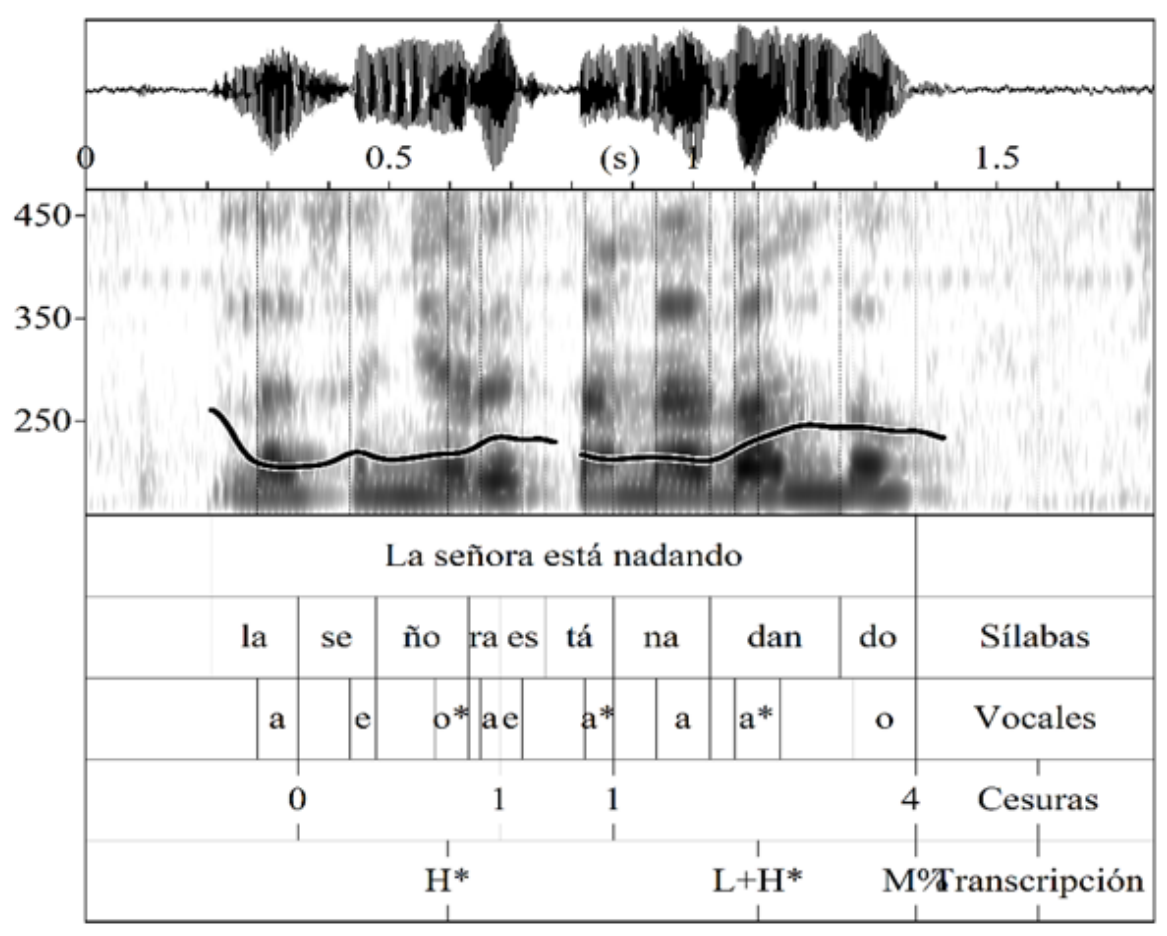

FIGURA 4.

Ejemplo de segmentación para el análisis de datos. La señora está nadando. HMQ2

En el etiquetado se tuvo en cuenta el movimiento de la curva tonal y la diferencia alcanzada en semitonos (st). De acuerdo con el criterio del umbral de percepción de 1.5 st. (Pamies Bertrán, Fernández Planas, Martínez Celdrán, Ortega Escandell y Amorós Céspedes, 2002; Murrieta Bello, 2016) ${ }^{11}$, los movimientos menores a 1.5 st. se transcribieron con monotonos $\left(\mathrm{H}^{*}, \mathrm{~L}^{*}, ! \mathrm{H}^{*}\right)$ y para los movimientos mayores a 1.5 st. se emplearon los bitonos $\left(\mathrm{L}+\left({ }_{i}\right) \mathrm{H}^{*}, \mathrm{~L}^{*}+\mathrm{H}, \mathrm{L}+>\mathrm{H}^{*}\right.$, para los ascensos; $\mathrm{y} \mathrm{H}+\mathrm{L}^{*}$, en los descensos). Para los tonos de juntura terminal, fueron utilizados los monotonos $\mathrm{L} \%$ para los descensos, $\mathrm{M} \%$ para los finales sostenidos ya sea altos o bajos, y H\% para los ascensos. Igualmente, se utilizaron las etiquetas $\mathrm{HL} \%$ y HM\%, para junturas complejas (Figura 2). Además se incluye el diacrítico $(i)$ para ascensos mayores a 3 st. A partir de los acentos en la sílaba nuclear y posnuclear, se realizó la prueba no paramétrica de Kruskal-Wallis, con el paquete estadístico $\operatorname{SPSS}(\mathrm{IBM}, 2013)$.

\section{Resultados}

\subsection{Enunciados declarativos en el español hablado por bilingües español-otomí}

Como se comentó en el apartado de metodología, dado el rasgo de espontaneidad de los datos colectados, el pretonema en los enunciados no está constituido por el mismo número de acentos tonales (AT). Por esta razón, se agruparon los datos de acuerdo con la cantidad de AT en este tramo del enunciado, es decir, desde la primera sílaba tónica hasta la sílaba que antecede la última tónica. Asimismo, los AT se organizaron para su comparación según el orden en que aparecen a partir de la primera sílaba tónica.

Las hablantes bilingües ( $\mathrm{HB}$ ) produjeron la mayor cantidad de enunciados conformados por dos (53) y tres (38) AT. Los resultados indican que, con independencia del número de AT que constituyen el enunciado, el acento sostenido $\mathrm{H}^{*}$ se presentó, en la mayoría de casos, con 64 ocurrencias seguido por el acento bitonal 
ascendente $\mathrm{L}+\mathrm{H}^{*}$ con 23 . Los acentos $\mathrm{L}+>\mathrm{H}^{*}$ y $\mathrm{L}^{*}$ presentaron menos apariciones y no tuvieron lugar en todos los enunciados (Tabla 3).

TABLA 3.

Acentos tonales en el pretonema de enunciados declarativos. Hablantes bilingües otomí-español

\begin{tabular}{|c|c|c|}
\hline Acentos & Primer AT & Segundo AT \\
\hline
\end{tabular}

\begin{tabular}{llclclc}
\hline Tres acentos & $\mathrm{H}^{*}$ & 22 & $\mathrm{H}^{*}$ & 36 & $\mathrm{H}^{*}$ & 35 \\
& $\mathrm{~L}+\mathrm{H}^{*}$ & 11 & $\mathrm{H}+\mathrm{L}^{*}$ & 1 & $\mathrm{~L}+\mathrm{H}^{*}$ & 1 \\
& $\mathrm{~L}+>\mathrm{H}^{*}$ & 5 & $\mathrm{~L}^{*}$ & 1 & $\mathrm{~L}^{*}$ & 2 \\
\hline Dos acentos & $\mathrm{H}^{*}$ & 34 & $\mathrm{H}^{*}$ & 43 & & \\
& $\mathrm{~L}+\mathrm{H}^{*}$ & 13 & $\mathrm{~L}+\mathrm{H}^{*}$ & 8 & & \\
& $\mathrm{~L}+>\mathrm{H}^{*}$ & 4 & $\mathrm{H}+\mathrm{L}^{*}$ & 2 & & \\
& $\mathrm{~L}^{*}$ & 2 & & & & \\
\hline Un acento & $\mathrm{H}^{*}$ & 8 & & & & \\
& $\mathrm{~L}^{*}$ & 1 & & & & \\
\hline Total & & 100 & & 91 & & \\
\hline
\end{tabular}

El tono $\mathrm{H}^{*}$ que resultó ser más frecuente en la primera posición se mantiene con esta frecuencia en la segunda y tercera posición de los enunciados conformados por más de un acento tonal. También se encontraron los acentos $\mathrm{L}+\mathrm{H}^{*}, \mathrm{H}+\mathrm{L}^{*}$ y $\mathrm{L}^{*}$ en las diferentes posiciones, sin embargo, revelaron muy pocas ocurrencias (en conjunto corresponden a 15 enunciados). Del total de posiciones posibles, el $77.7 \%$ corresponden al tono $\mathrm{H}^{*}$, el $33 \%$ al tono $\mathrm{L}+\mathrm{H}^{*}$; los tonos $\mathrm{L}+>\mathrm{H}^{*}(3.9 \%), \mathrm{L}^{*}(2.6)$ y $\mathrm{H}+\mathrm{L}^{*}(1.31 \%)$ presentaron menor porcentaje de aparición. En términos generales, la revisión de los datos indica que el pretonema presenta un inicio alto que se mantiene a lo largo del enunciado hasta llegar al tonema.

Por su parte, la configuración del tonema en las HB reveló dos acentos nucleares de mayor frecuencia. El primer acento con mayor número de casos es el bitonal ascendente $\mathrm{L}+\mathrm{H}^{*}$ con 74 casos, en segundo lugar, aparece el acento $\mathrm{H}^{*}$ con 26. De igual manera, se registraron dos tonos de juntura terminal, L\% y $\mathrm{M}$ $\%$, que alcanzaron valores frecuenciales bastante cercanos con 45 y 42 casos, respectivamente. Aunque con muy pocas apariciones, también se presentaron los bitonos HL\% y HM\%, que básicamente indican una prolongación del ascenso desde la sílaba nuclear seguido por un descenso o por un sostenimiento en la última sílaba del enunciado, respectivamente (Tabla 4). 
Eva Patricia Velásquez Upegui. Entonación de enunciados declarativos en el español hablado en Quer...

TABLA 4.

Acento nuclear y juntura terminal de enunciados declarativos. Hablantes bilingües otomí-español

\begin{tabular}{cccccc}
\hline $\begin{array}{c}\text { Acento } \\
\text { Nuclear/Juntura }\end{array}$ & L\% & M\% & HM\% & HL\% & Total \\
\hline L+H* & 35 & 30 & 2 & 7 & 74 \\
$\mathrm{H}^{*}$ & 10 & 12 & 2 & 2 & 26 \\
\hline Total & 45 & 42 & 4 & 9 & 100 \\
\hline
\end{tabular}

La configuración nuclear que caracteriza los enunciados declarativos de este grupo de hablantes, corresponde al acento tonal ascendente $\mathrm{L}+\mathrm{H}^{*}$ con finales descendentes $\mathrm{L} \%$ (Figura 5), esta misma configuración se ha reportado en diferentes variedades del español de México (Tabla 1). En cuanto al ascenso alcanzado en semitonos en el acento $\mathrm{L}+\mathrm{H}^{*}, 49$ casos de 74 en total $(66 \%)$ están en el rango de 1.5 st. a 3 st. Los 25 casos restantes ( $34 \%$ ) se ubican entre los 3 st. y 6 st., los cuales, desde una perspectiva más fonética, podrían ser representados como $\mathrm{L}+{ }_{i} \mathrm{H}^{*}$, es decir un ascenso mayor a lo esperado.

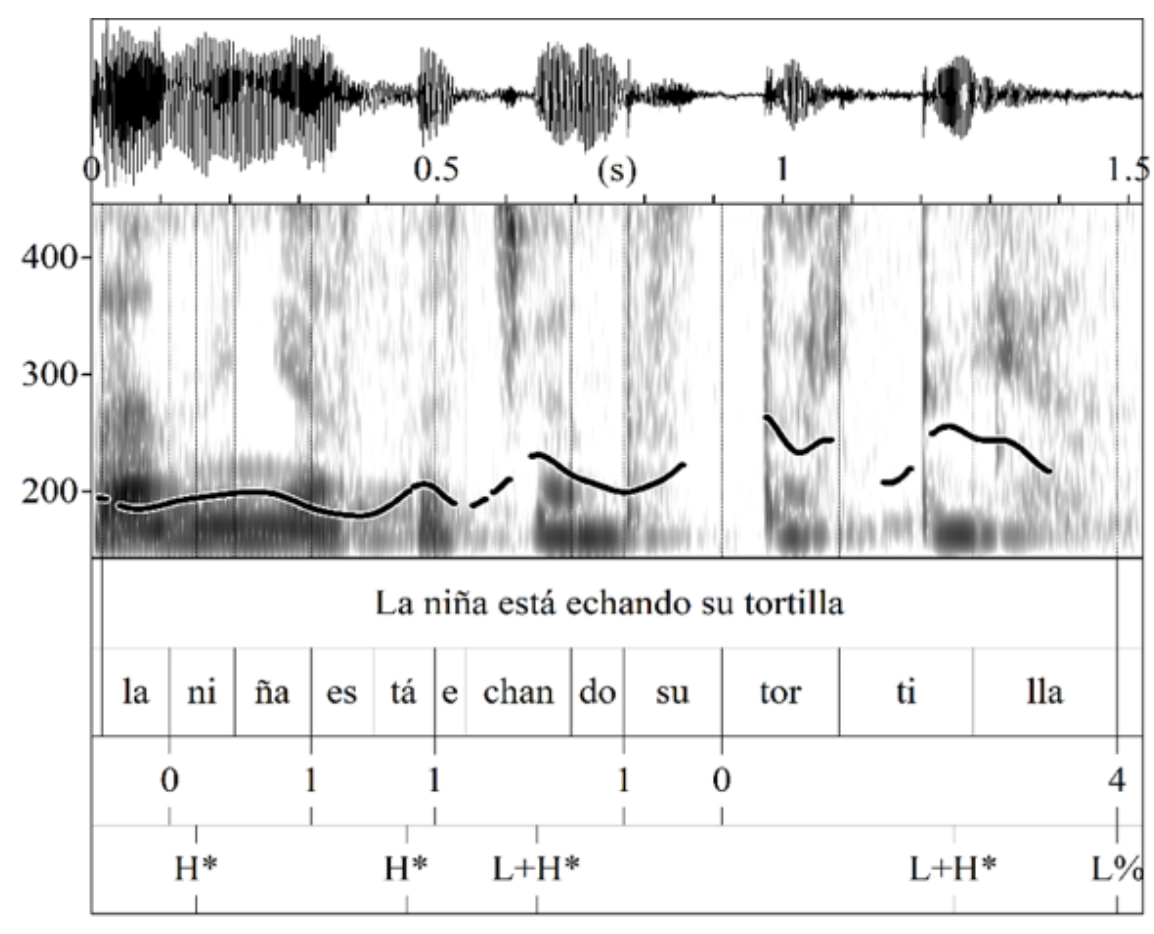

FIGURA 5.

La niña está echando tortillas. HB2 


\subsection{Enunciados declarativos en el español hablado por monolingües de Amealco}

Las hablantes monolingües de Amealco (HMA) produjeron 7 enunciados con tres acentos tonales en el pretonema, 43 enunciados con dos acentos tonales, y 50 enunciados con un acento tonal. En todas las producciones, la mayor frecuencia en el primer acento tonal corresponde a $\mathrm{H}^{*}$ con un total de 83 ocurrencias. En mucho menor proporción se encuentran el acento $\mathrm{H}+\mathrm{L}^{*}$ con 8 realizaciones, seguido por $\mathrm{L}+>\mathrm{H}^{*} \operatorname{con} 6$ y L $+\mathrm{H}^{*}$ con 2 (Tabla 5).

TABLA 5.

Acentos tonales en el pretonema de los enunciados declarativos. Hablantes monolingües de Amealco

\begin{tabular}{|c|c|c|c|c|c|c|}
\hline \multirow{2}{*}{$\begin{array}{l}\text { Acentos tonales } \\
\text { Tres acentos }\end{array}$} & \multicolumn{2}{|c|}{ Primer AT } & \multicolumn{2}{|c|}{ Segundo AT } & \multicolumn{2}{|c|}{ Tercer AT } \\
\hline & $\mathrm{H}^{*}$ & 4 & $\mathrm{H}^{*}$ & 6 & $\mathrm{H}^{*}$ & 6 \\
\hline & $\mathrm{L}+>\mathrm{H}^{*}$ & 3 & $\mathrm{~L}+>\mathrm{H}^{*}$ & 1 & $\mathrm{H}+\mathrm{L}^{*}$ & 1 \\
\hline \multirow[t]{3}{*}{ Dos acentos } & $\mathrm{H}^{*}$ & 39 & $\mathrm{H}^{*}$ & 39 & & \\
\hline & $\mathrm{H}+\mathrm{L}^{*}$ & 2 & $\mathrm{H}+\mathrm{L}^{*}$ & 3 & & \\
\hline & $\mathrm{L}+>\mathrm{H}^{*}$ & 2 & $\mathrm{~L}+\mathrm{H}^{*}$ & 1 & & \\
\hline \multirow[t]{4}{*}{ Un acento } & $\mathrm{H}^{*}$ & 40 & & & & \\
\hline & $\mathrm{H}+\mathrm{L}^{*}$ & 7 & & & & \\
\hline & $\mathrm{L}+\mathrm{H}^{*}$ & 2 & & & & \\
\hline & $\mathrm{L}+>\mathrm{H}^{*}$ & 1 & & & & \\
\hline Total & & 100 & & 50 & & 7 \\
\hline
\end{tabular}

Los tonos en el cuerpo del enunciado de las producciones conformadas por tres y dos acentos tonales revelan una preferencia por tonos sostenidos $\mathrm{H}^{*}$ en la segunda y tercera posición, también se presentaron los acentos $\mathrm{H}+\mathrm{L}^{*}, \mathrm{~L}+>\mathrm{H}^{*}$ y $\mathrm{L}+\mathrm{H}^{*}$, aunque con pocas ocurrencias. El $85.35 \%$ de las posiciones posibles corresponden al tono $\mathrm{H}^{*}$, seguido por $\mathrm{H}+\mathrm{L}^{*} \operatorname{con} 8.28 \%, \mathrm{~L}+>\mathrm{H}^{*}$ con $4.45 \%$ y por último $\mathrm{L}+\mathrm{H}^{*}$ con el $1.9 \%$. Como en el caso de las hablantes bilingües, los enunciados declarativos revelan una tendencia a presentar un primer tono ascendente con una continuidad sostenida en el trayecto hacia el tonema.

Con respecto a la configuración del tonema en los enunciados producidos por las HMA, se observa un porcentaje muy cercano en el uso de dos acentos nucleares $\mathrm{H}^{*}$ y $\mathrm{L}+\mathrm{H}^{*}$. El acento nuclear sostenido también se ha documentado en Baja California Sur (Tabla 1). Por su parte, los tonos de juntura terminal tuvieron un mayor porcentaje de finales sostenidos M\%, seguido por el bitono HM\%, es decir, con una continuidad del ascenso desde la sílaba nuclear más una culminación sostenida (Tabla 6). Los finales sostenidos también se presentan en Michoacán, Monterrey y Guadalajara (Tabla 1). 
TABLA 6.

Tonos y junturas de enunciados declarativos. Hablantes monolingües de Amealco

\begin{tabular}{cccccc}
\hline $\begin{array}{c}\text { Acento } \\
\text { Nuclear/Juntura }\end{array}$ & L\% & M\% & HM\% & HL\% & Total \\
\hline $\mathrm{H}^{*}$ & 5 & 24 & 19 & 1 & 49 \\
L $+\mathrm{H}^{*}$ & 3 & 28 & 15 & 1 & 47 \\
$\mathrm{~L}^{*}$ & 1 & 3 & 0 & 0 & 4 \\
\hline Total & 13 & 50 & 34 & 3 & 100 \\
\hline
\end{tabular}

De acuerdo con los resultados obtenidos (Tabla 6), la configuración nuclear en los enunciados producidos por las hablantes de Amealco podría representarse con dos patrones; en primer lugar $\mathrm{H}^{*} \mathrm{M} \%$ o $\mathrm{HM} \%$, y en segundo lugar, $\mathrm{L}+\mathrm{H}^{*} \mathrm{M} \%{ }^{12}$ (Figura 6). Con relación a los acentos $\mathrm{L}+\mathrm{H}^{*}, 34$ enunciados están en el rango los 1.5 st. y 3 st. (74\%), 12 enunciados están entre los 3 st y 6 st. (56 \%), y solo en uno alcanzan los 7 st. La realización $\mathrm{H}^{*}$ también se ha reportado en los datos enunciados declarativos producidos por hablantes de Baja California Sur. Por su parte, los finales M\% también se comparten con las variedades de Michoacán, Guadalajara y Monterrey (Tabla 1).

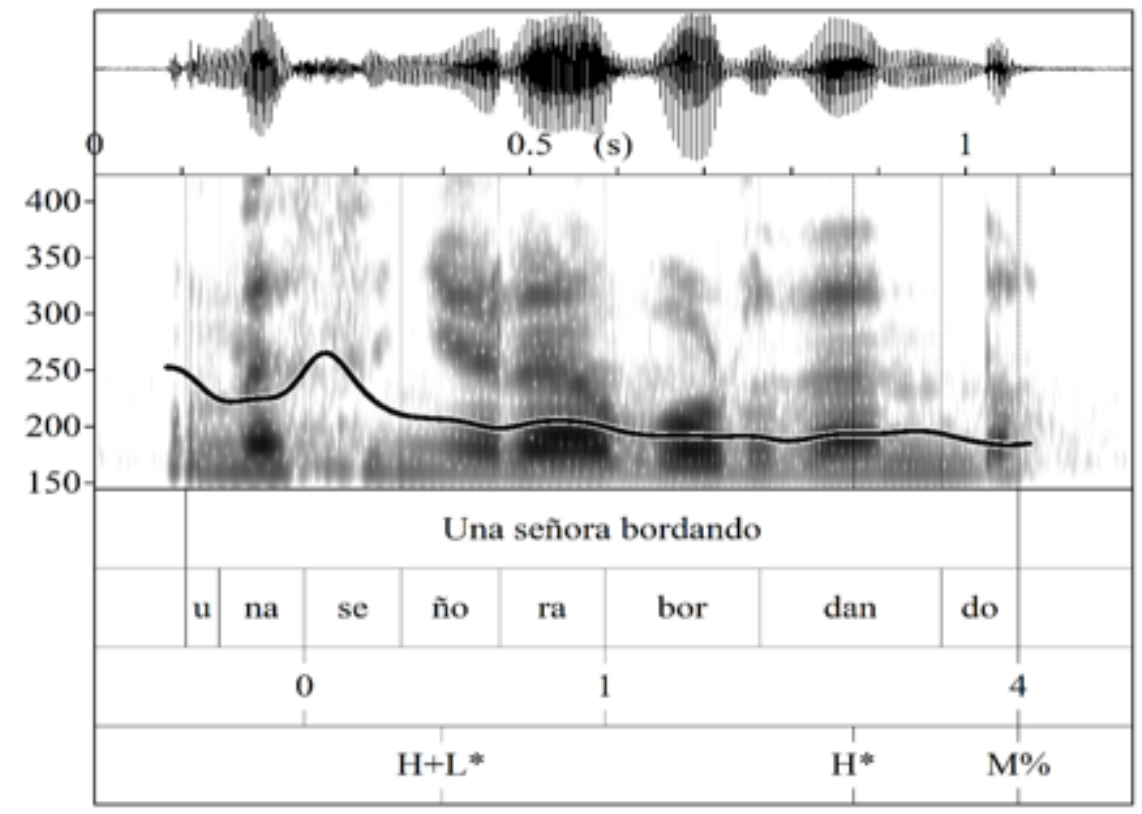

FIGURA 6.

Una señora bordando. HMA1

\subsection{Enunciados declarativos en el español hablado por monolingües de Querétaro}

Las producciones de las hablantes monolingües de Querétaro (HMQ) revelaron 11 enunciados con tres acentos tonales, 60 enunciados con dos y 29 enunciados con un acento tonal en el pretonema. El acento tonal 
inicial presentó dos realizaciones recurrentes en los diferentes enunciados, $\mathrm{H}^{*}$ y $\mathrm{L}+>\mathrm{H}^{*}$, la más frecuente corresponde al primer acento con 77 casos. En segundo lugar, con 18 casos se documentan picos desplazados $\mathrm{L}+>\mathrm{H}^{*}$, y solo con 3 y 2 ocurrencias, aparecen los acentos $\mathrm{L}+\mathrm{H}^{*}$ y $\mathrm{L}^{*}+\mathrm{H}$ (Tabla 7 ). Por su parte, la segunda y tercera posición de AT la ocupan los tonos ${ }_{i} \mathrm{H}^{*}$ y $\mathrm{H}^{*}$. En ambas posiciones, el tono de mayor frecuencia es $! \mathrm{H}^{*}$ seguido por $\mathrm{H}^{*}$.

TABLA 7.

Acentos tonales en el pretonema de los enunciados declarativos. Hablantes monolingües de Querétaro

\begin{tabular}{|c|c|c|c|c|c|c|}
\hline \multirow{2}{*}{$\begin{array}{l}\text { Acentos tonales } \\
\text { Tres acentos }\end{array}$} & \multicolumn{2}{|c|}{ Primer AT } & \multicolumn{2}{|c|}{ Segundo AT } & \multicolumn{2}{|c|}{ Tercer AT } \\
\hline & $\mathrm{L}+>\mathrm{H}^{*}$ & 6 & $\mathrm{H}^{*}$ & 9 & $! \mathrm{H}^{*}$ & 6 \\
\hline & $\mathrm{H}^{*}$ & 5 & $! \mathrm{H}^{*}$ & 2 & $\mathrm{H}^{*}$ & 5 \\
\hline \multirow[t]{4}{*}{ Dos acentos } & $\mathrm{H}^{*}$ & 47 & $! \mathrm{H}^{*}$ & 38 & & \\
\hline & $\mathrm{L}+>\mathrm{H}^{*}$ & 9 & $\mathrm{H}^{*}$ & 22 & & \\
\hline & $L^{*}+\mathrm{H}$ & 2 & & & & \\
\hline & $\mathrm{L}+\mathrm{H}^{*}$ & 2 & & & & \\
\hline \multirow[t]{3}{*}{ Un acento } & $\mathrm{H}^{*}$ & 25 & & & & \\
\hline & $\mathrm{L}+>\mathrm{H}^{*}$ & 3 & & & & \\
\hline & $\mathrm{L}+\mathrm{H}^{*}$ & 1 & & & & \\
\hline Total & & 100 & & 71 & & 11 \\
\hline
\end{tabular}

En el trayecto del acento inicial al acento nuclear son comunes los tonos sostenidos. En algunos casos, los acentos pueden ser menos altos que los acentos circundantes sin llegar a tratarse de un descenso, por esta razón, se han representado como $! \mathrm{H}^{*}$, es decir, un ascenso menor a lo esperado. Este acento se presentó en los enunciados conformados por tres y dos acentos tonales (Tabla 7). En relación con la frecuencia de tonos posibles en las distintas posiciones, el AT más frecuente corresponde a $\mathrm{H}^{*}$ con el $62.5 \%$, seguido por el tono! $\mathrm{H}^{*}$ con $25 \%$, con más bajos promedios de aparición están los AT $\mathrm{L}+>\mathrm{H}^{*}(9.78 \%), \mathrm{L}^{*}+\mathrm{H}(1.08 \%)$ y L* $+\mathrm{H}$ $(1.63 \%)$. En términos generales, podría decirse que el pretonema de estos enunciados presenta un primer acento tonal alto seguido por descensos moderados a lo largo del enunciado.

En cuanto al tonema, la configuración más frecuente corresponde al acento nuclear ascendente $\mathrm{L}+\mathrm{H}^{*}$ con 62 casos, seguido por el acento $\mathrm{H}^{*}$ con 28 . Por su parte, el tono de juntura terminal de mayor ocurrencia es sostenido M\% con 73 ocurrencias, la juntura descendente L\% y la juntura bitonal HM\% presentan 11 y 15 realizaciones, respectivamente (Tabla 8 ). 
TABLA 8.

Tonos y junturas de enunciados declarativos. Hablantes monolingües de Querétaro

\begin{tabular}{cccccc}
\hline $\begin{array}{c}\text { Acento } \\
\text { Nuclear/Juntura }\end{array}$ & $\mathrm{L} \%$ & $\mathrm{M} \%$ & $\mathrm{HM} \%$ & $\mathrm{HL} \%$ & Total \\
\hline $\mathrm{L}+\mathrm{H}^{*}$ & 9 & 41 & 11 & 1 & 62 \\
$\mathrm{H}^{*}$ & 2 & 22 & 4 & 0 & 28 \\
$\mathrm{~L}^{*}$ & 0 & 10 & 0 & 0 & 10 \\
\hline Total & 11 & 73 & 15 & 1 & 100 \\
\hline
\end{tabular}

De acuerdo con los resultados agrupados en la Tabla 8, la configuración nuclear preferida en las hablantes queretanas corresponde a $\mathrm{L}+\mathrm{H}^{*} \mathrm{M} \%$ (Figura 7 ). El tono nuclear $\mathrm{L}+\mathrm{H}^{*}$ ha sido ampliamente documentado en distintas variedades del país, sin embargo, la juntura $\mathrm{M} \%$, como ya se mencionó, solo se ha encontrado en Michoacán, Guadalajara y Monterrey (Tabla 1). Desde el punto de vista fonético, el AT ascendente $\mathrm{L}+\mathrm{H}^{*}$ presenta 37 de las 62 realizaciones ubicada entre los 1.5 st y 3 st (60\%). Los 25 enunciados restantes se ubican entre los 3 st y 6 st, estos podrían representarse como $\mathrm{L}+{ }_{i} \mathrm{H}^{*}(40 \%)$, y solo dos enunciados alcanzaron los 7 st.

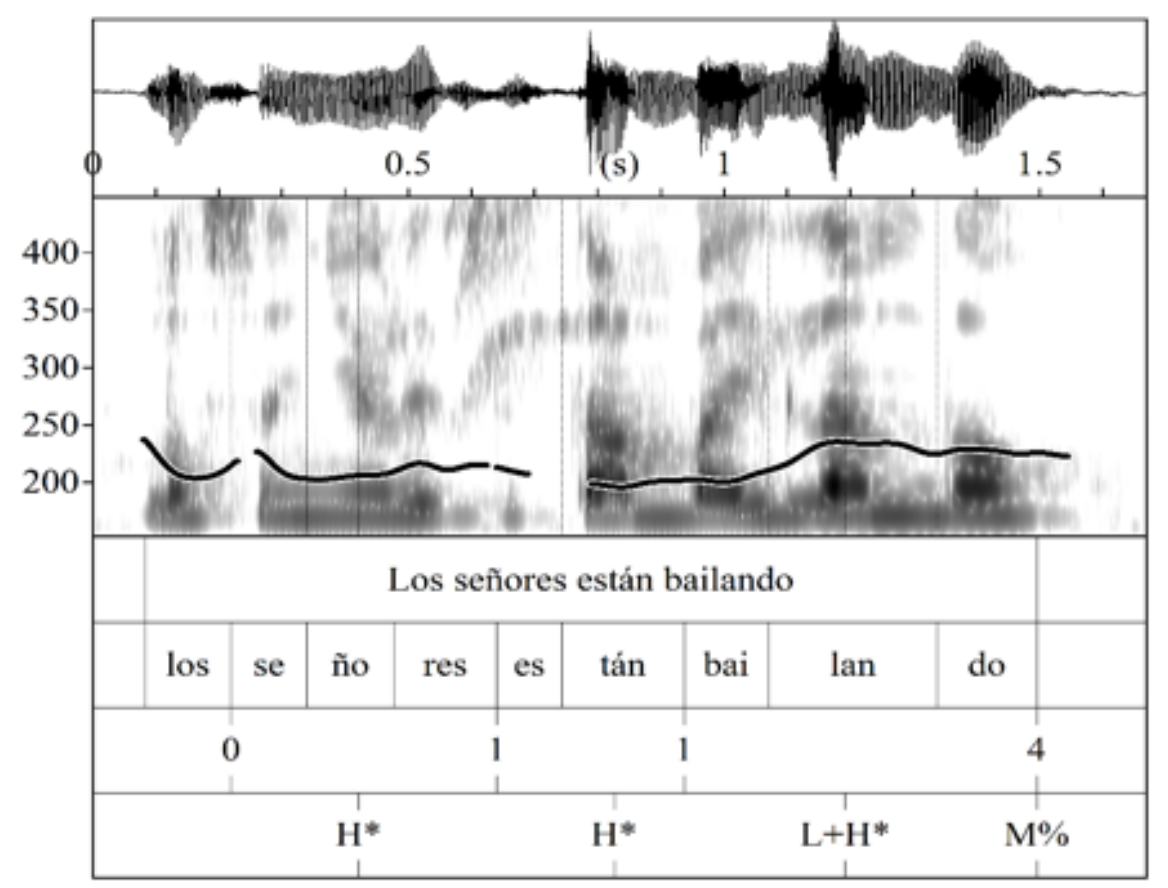

FIGURA 7.

Los señores están bailando. HMQ3

\subsection{Convergencias y divergencias en la entonación de los enunciados declarativos}

La revisión realizada permite trazar algunas coincidencias entre los enunciados producidos por las hablantes bilingües (HB), las monolingües de Amealco (HMA) y Querétaro (HMQ). En cuanto al pretonema ${ }^{13}$, los 
tres grupos de hablantes mostraron preferencia por un primer acento tonal alto $\mathrm{H}^{*}$, que predominó en las HMA en comparación con las HB y HMQ. Aunque con pocas ocurrencias, los tres grupos de hablantes presentaron acentos tonales particulares no compartidos entre grupos. Por ejemplo, las HMA revelaron el acento tonal $\mathrm{H}+\mathrm{L}^{*}$. De igual forma, en las $\mathrm{HB}$ se presenta el tono $\mathrm{L}^{*}$ y en las $\mathrm{HMQ}$, el acento $\mathrm{L}^{*}+\mathrm{H}$ (Figura 8).

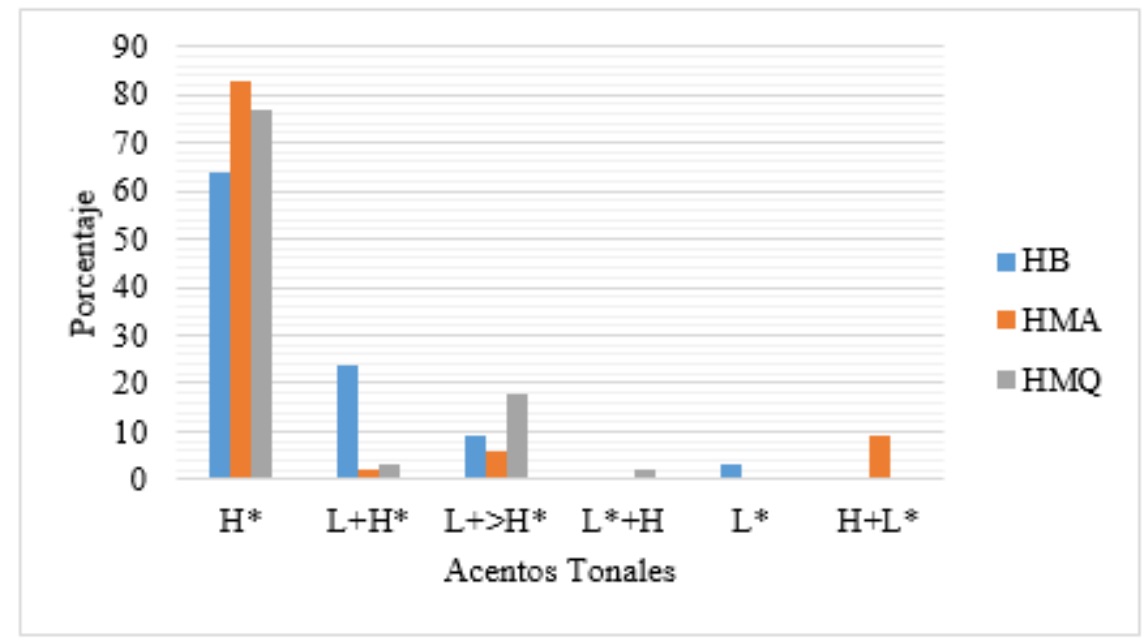

FIGURA 8.

Primer acento tonal en los tres grupos de hablantes en el estado de Querétaro

El segundo acento tonal en el cuerpo del enunciado reveló similitud entre las HB y HMA en cuanto a la preferencia por el acento tonal $\mathrm{H}^{*}$, es decir, un tono alto sostenido, a diferencia de las HMQ que mostraron un mayor uso de $! \mathrm{H}^{*}$ que indica un descenso moderado. Las hablantes de los tres grupos mostraron una tendencia a preferir los tonos sostenidos $\mathrm{H}^{*}$, sin embargo, el grupo de las $\mathrm{HB}$ también muestra en muy pocas ocurrencia los tonos $\mathrm{L}+\mathrm{H}^{*}, \mathrm{H}+\mathrm{L}^{*}$ y $\mathrm{L}^{*}$ (Figura 9).

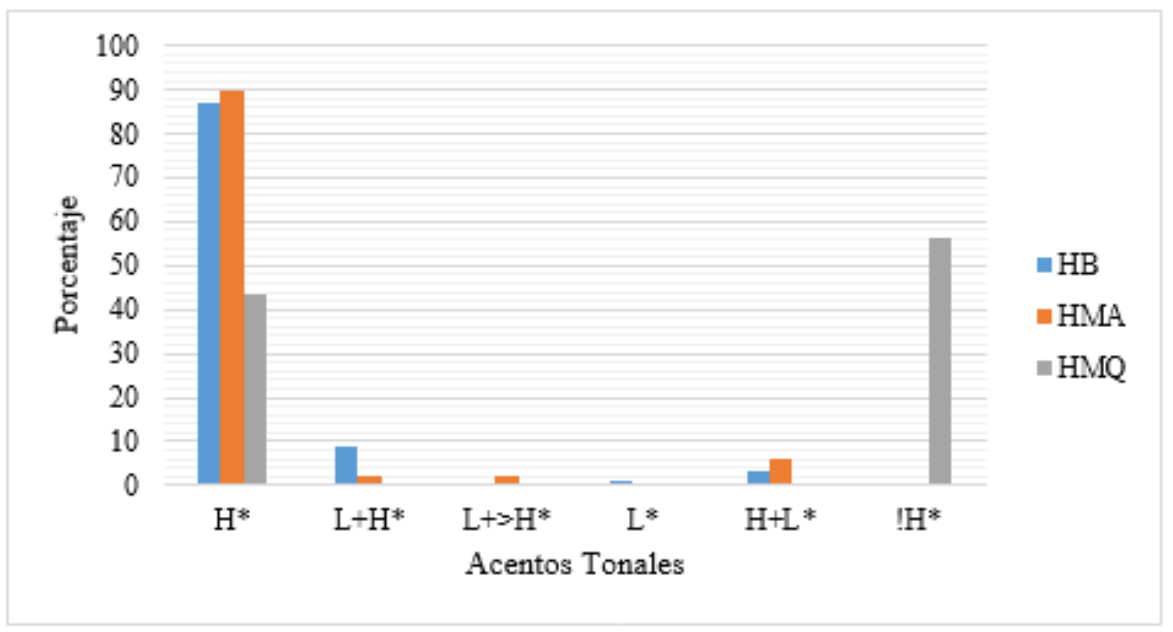

FIGURA 9.

Segundo acento tonal en los tres grupos de hablantes en el estado de Querétaro

Por su parte, el tercer acento tonal en el cuerpo del enunciado nuevamente presenta una preferencia de las hablantes por el tono $\mathrm{H}^{*}$, en el grupo de las $\mathrm{HMQ}$ se registra un uso frecuente del acento $! \mathrm{H}^{*}$. Los demás tonos $\mathrm{L}+\mathrm{H}^{*}, \mathrm{~L}^{*}$ y H$+\mathrm{L}^{*}$ no tuvieron muchas realizaciones en las diferentes hablantes (Figura 10). 


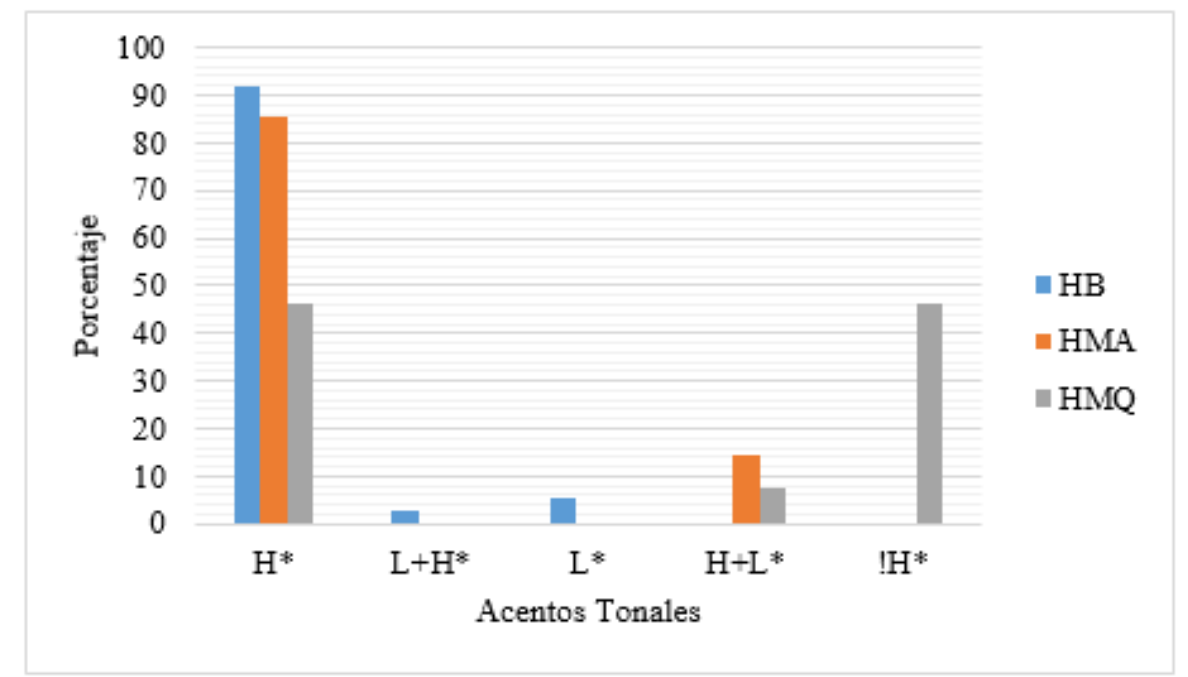

FIGURA 10.

Tercer acento tonal en los tres grupos de hablantes en el estado de Querétaro

Con relación al acento nuclear, el tono $\mathrm{L}+\mathrm{H}^{*}$ reveló mayor uso en las $\mathrm{HB}$ y HMQ (Figura 11). En las $\mathrm{HMA}$, el acento $\mathrm{H}^{*}$ resultó ligeramente más frecuente. Con respecto a la realización bitonal, en el caso de las HMQ los ascensos entre 3 st. y 6 st., que pueden ser representados como $\mathrm{L}+(\mathrm{i}) \mathrm{H}^{*}$, corresponden con el $60 \%$ de los bitonos ascendentes, mientras que en las $\mathrm{HB}$ ocurre en el $34 \%$ de los casos, lo que revela que en las HMQ son característicos los ascensos mayores a lo esperado en comparación con las demás hablantes, aunque son las $\mathrm{HB}$ quienes presentan un porcentaje mayor de $\mathrm{L}+\mathrm{H}^{*}$.

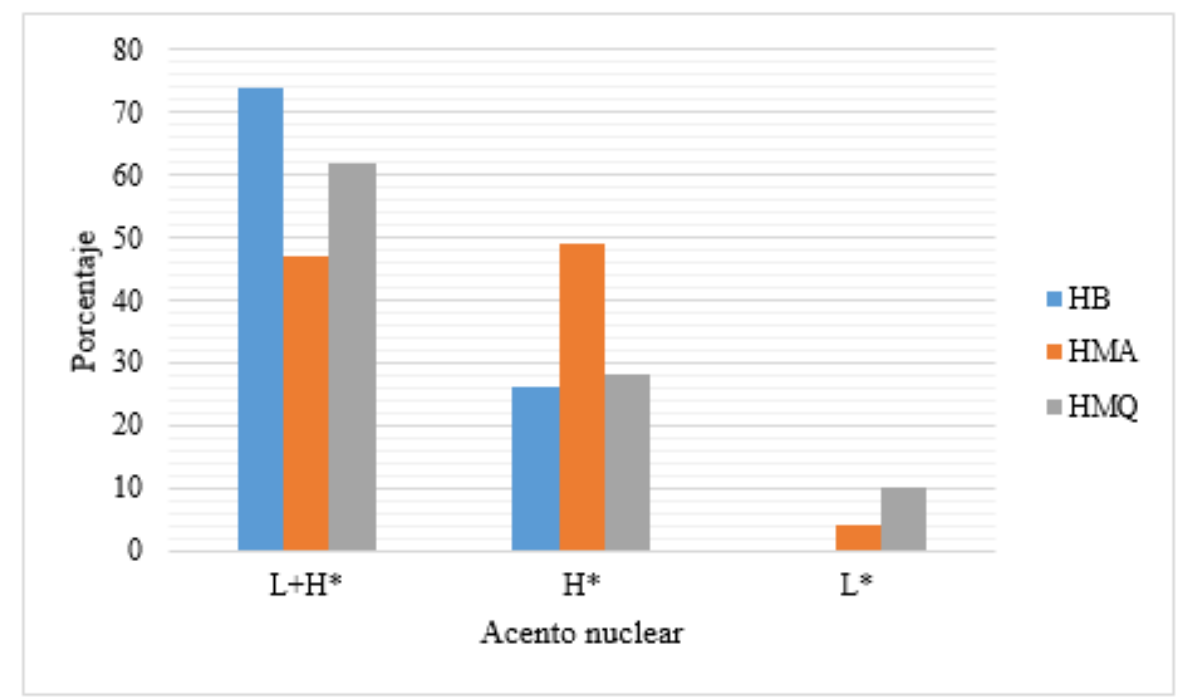

FIGURA 11.

Acento nuclear en los tres grupos de hablantes en el estado de Querétaro

La comparación de los acentos nucleares, de acuerdo con la prueba no paramétrica de Kruskal-Wallis, arrojó diferencias estadísticamente significativas entre los grupos de hablantes $(\mathrm{X} 2(2)=10.425, \mathrm{p}=0.05)$. Los resultados entre pares no revelaron diferencias entre los grupos de $\mathrm{HB}$ y $\mathrm{HMQ}$, sin embargo, las hablantes HMA se diferenciaron de los demás grupos. Estos resultados indican que el acento nuclear $\mathrm{L}+\mathrm{H}^{*}$ se comparte con la mayoría de hablantes en la región, principalmente en las hablantes bilingües y queretanas ${ }^{14}$. 


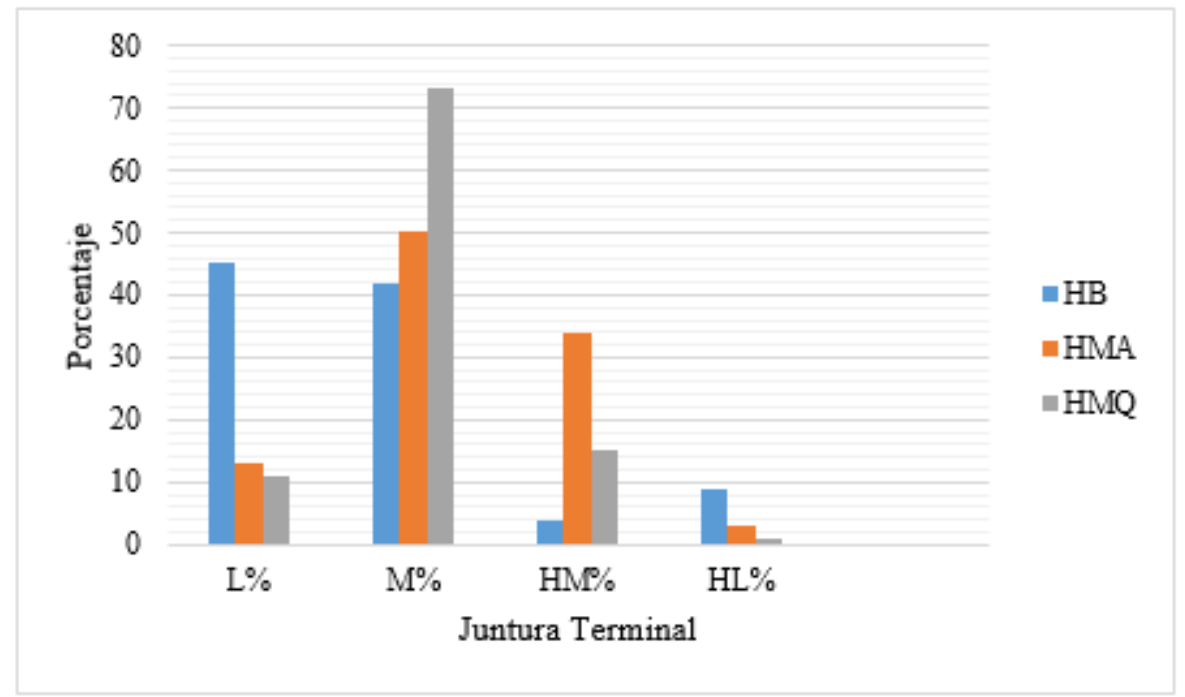

FIGURA 12.

Juntura terminal en los tres grupos de hablantes en el estado de Querétaro

Por su parte, la juntura terminal M\%, es utilizada en los tres grupos de hablantes, no obstante, las HB revelan una alternancia con junturas descendentes L\% a diferencia de las HMQ y HMA que muestran preferencia uso de finales M\% y, en el caso de las HMA, también se presentaron los bitonos HM \%. Los resultados de la prueba de Kruskal-Wallis mostraron diferencias estadísticamente significativas entre grupos $(\mathrm{X} 2(2)=10.569, \mathrm{p}=0.05)$. Las comparaciones por pares indican diferencias entre $\mathrm{HB}$ y HMQ, exclusivamente. Las hablantes bilingües presentan una preferencia por los descensos probablemente asociados al contacto de lenguas, dado que las hablantes no bilingües presentaron un tendencia al uso de tonos sostenidos (Figura 12).

\section{Conclusiones}

El objetivo de este trabajo fue determinar la entonación en enunciados declarativos en el español de Querétaro a partir de la descripción de estos enunciados en tres grupos de hablantes: hablantes bilingües español-otomí, las hablantes monolingües de Amealco, y de Querétaro; para reconocer sus diferencias y similitudes. La revisión de los datos de los tres grupos de hablantes HB, HMA, HMQ permite plantear ciertas generalidades en cuanto al español queretano como:

i. Inicio de los enunciados típicamente alto, por encima de la línea media de las hablantes,

ii. el trayecto del tono en el pretonema transcurre de manera sostenida,

iii. el tonema se caracteriza por presentar un acento nuclear bitonal ascendente $\mathrm{L}+(\mathrm{i}) \mathrm{H}^{*}, \mathrm{y}$

iv. la juntura del terminal es con frecuencia sostenida $\mathrm{M} \%$.

La realización del acento nuclear $\mathrm{L}+\mathrm{H}^{*}$ (Figura 13), reportada en la variedad del español queretano, coincide con las descripciones del español de la Ciudad de México (Martín-Butragueño, 2004, 2006a, 2006b); Cuapiaxtla/Tlaxcala (Mendoza Vázquez, 2014), Michoacán (Coronado Hernández, 2014), Baja California Sur (Gil Burgoin, 2011, 2017), Monterrey (Gil Burgoin, 2017), Tuxtla (Mendoza Vázquez, 2019) y Oaxaca (Martín Butragueño, 2019) (Tabla 1), en este sentido, el español de Querétaro se vincula con la tendencia mayoritaria hasta ahora documentada en el país.

Con respecto a la juntura terminal, el final sostenido M\% (Figura 13), también se ha encontrado en algunas variedades como Michoacán (Coronado Hernández, 2014), Guadalajara (Gil Burgoin, 2017; Orozco, 2016; 
Radillo Enríquez, 2011) y Monterrey (Montellano Moreno, 2017), sin embargo, la mayoría de estudios sobre el español mexicano realizados hasta el momento mencionan, con mayor frecuencia, la juntura L\% (Tabla 1). Por su parte, el tonema $\mathrm{L}+{ }_{¡} \mathrm{H}^{*} \mathrm{M} \%$ común en la variedad de Querétaro, solo ha sido atribuido al español de Michoacán (Coronado Hernández, 2014).

Como se reveló a lo largo del presente estudio, las variedades queretanas muestran características prosódicas que marcan diferencias al interior de esta comunidad. En cuanto al tono nuclear, las HMQ presentaron con mayor frecuencia ascensos mayores a 3 st. en comparación con las HB y las HMA, a su vez, estás últimas hablantes presentaron un uso generalizado de acentos sostenidos $\mathrm{H}^{*}$. En cuanto a la juntura terminal las HB revelaron mayor uso de finales tipo L\% (Figura 13).

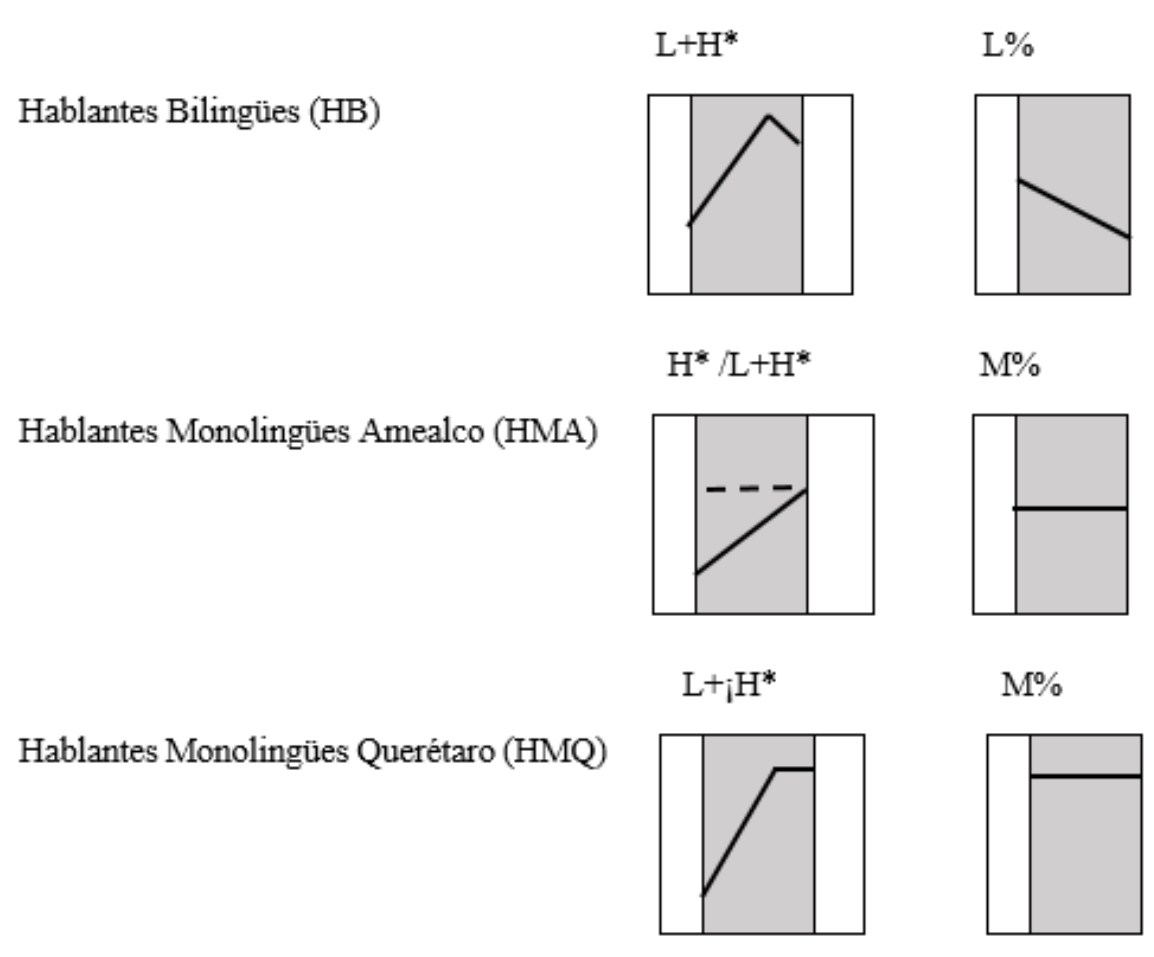

FIGURA 13.

Tonema en los enunciados declarativos de los tres grupos de hablantes en el estado de Querétaro

\section{BibLIOgRAFÍA}

Alvarellos, M., Muñiz-Cachón, C., Díaz, L. y González, R. (2011). La entonación en las variedades lingüísticas de Asturias: estudio contrastivo. Revista internacional de lingüistica iberoamericana, 17, 111-120.

Bermeo, V. (2011). La vitalidad del otomí en Santiago Mexquititlán, Querétaro. En R. Terborg y L. García (Eds.), Muerte y vitalidad de las lenguas indigenas y las presiones sobre sus hablantes (pp. 177-195). Ciudad de México: UNAM-CELE.

Birdsong, D., Gertken, L. M. y Amengual, M. (2012). Bilingual Language Profile: An Easy-to-Use Instrument to Assess Bilingualism. COERLL, University of Texas at Austin. Recuperado de https://sites.la.utexas.edu/bilingual/

Boersma, P. y Weenink, D. (1992). Praat: doing phonetics by computer. Universidad de Amsterdam. Recuperado de h ttp://www.fon.hum.uva.nl/praat/

Castillo, L. (s. f.). Prepararse para ser madre. Grupo Reforma. Recuperado de https://gruporeforma.reforma.com/imd/aplicacioneslibre/grafico/default.aspx?id=2687\&md5=c365cd7f1 99bbf5486d06909b8093064\&ta=0dfdbac11765226904c16cb9ad1b2efe 
Comisión Nacional para el Desarrollo de los Pueblos Indigenas. (2009). Panorama socioeconómico de la población indígena de Querétaro. En Proyecto CDI-PNUD 00047120. Recuperado de https://fdocuments.mx/document /panorama-socioeconomico-de-la-poblacion-indigena-de-queretaro.html

Congosto Martín, Y. (2019). Political vs. linguistic borders The Spanish intonation of Mexicans and Mexican Americans living on either side of the border. Spanish in Context, 16(3), 90-418.

Congosto Martín, Y. (2020). Guatemalan Spanish in contact: Prosody and intonation. Estudios de Fonética Experimental, 29, 153-194.

Congosto Martín, Y. y Morgenthaler, L. (2019). Prosodic issues in language contact situations. Spanish in Context, 16(3), 323-328.

Coronado Hernández,J. (2014). Entonación rural del español de México. En P. Martín Butragueño y L. Orozco (Eds.), Argumentos cuantitativos y cualitativos en sociolingüistica (pp. 61-78). El Colegio de México.

Cuevas Alonso, M. y López Bobo, M. J. (2011). Dialectos en contacto y prosodia. Análisis contrastivo de la entonación del oriente y occidente de Cantabria. Revista Internacional de Linguistica Iberoamericana, 9(1), 39-51.

Cuevas Alonso, M. y Míguez-Álvarez, C. M. (2019). La entonación del español de Cantabria de oriente a occidente. Las interrogativas absolutas. Moenia, 25, 597-617.

De-la-Mota, C., Martín Butragueño, P. y Prieto, P. (2010). Mexican Spanish intonation. En P. Prieto y P. Roseano (Eds.), Transcription of Intonation of the Spanish Language (pp. 319-350). Münich: Lincom.

Elejabeitia, A., Iribar, A. y Pagola, R. M. (2008). La prosodia del castellano en tres ciudades vascas: oraciones con y sin expansión. Language Design: Journal of Theoretical and Experimental Linguistics, 10, 157-164.

Estebas-Vilaplana, E. y Prieto, P. (2008). La notación prosódica del español: una revisión del Sp_ToBI. Estudios de Fonética Experimental, 17, 263-283. Recuperado de https://core.ac.uk/download/pdf/39111168.pdf

Figueria, D. (2001). Otomies de Querétaro. Proyecto perflles indígenas de México. Recuperado de https://www.aacade mica.org/salomon.nahmad.sitton/67

Frota, S. y Prieto, P. (2015). Intonation in Romance: Systemic similarities and differences. En S. Frota y P. Prieto (Eds.), Intonation in Romance (pp. 392-418). Inglaterra: Oxford University Press.

Gabriel, C. y Kireva, E. (2014). Prosodic transfer in learner and contact varietird. Studies in second language acquisition, $36,257-281$.

Gil Burgoin, C. I. (2011). El español del municipio de La Paz, Baja California Sur: variación fónica y entonativa. (Tesis de Licenciatura). Escuela Nacional de Antropología en Historia.

Gil Burgoin, C. I. (2017). La entonación de los enunciados declarativos neutros en cinco variedades del español mexicano: una búsqueda de hipótesis dialectales. En L. Orozco y A. Guerrero Galván (Eds.), Estudios de variación geolingüistica (pp. 227-250). Ciudad de México: Instituto Nacional de Antropología e Historia.

Guerrero Galván, A. (2015). Patronea tonales y acento en otomí. En E. Zendejas (Ed.), Tono, acentos y estructuras métricas en lenguas mexicanas (pp. 235-260). México: El Colegio de México.

Gussenhoven, C. (2004). The Phonology of Tone and Intonation. Inglaterra: Cambridge University Press.

Gutiérrez Bravo, R. (2008). La identificación de los tópicos y los focos. Nueva Revista de Filología Hispánica, 56, 363-401. Recuperado de https://nrfh.colmex.mx/index.php/nrfh/article/view/969

Hekking, E. y Andrés de Jesús, S. (1984). Gramática otomí. México: Universidad Autónoma de Querétaro.

Hualde, J. I. (2003). El modelo métrico y autosegmental. En P. Prieto (Ed.), Teorias de la entonación (pp. 155-184). Barcelona: Ariel.

Hualde, J. I. y Prieto, P. (2015). Intonational Variation in Spanish: European and American varieties. En S. Frota y P. Prieto (Eds.), Intonational Variation in Romance (pp. 350-391). Inglaterra: Oxford University Press.

INEGI. (2015). Censo de población y vivienda. Recuperado de https://www.inegi.org.mx/programas/ccpv/2020/

IBM. (2013). SPSS Statistics for Windows (22.0). New York: IBM Corp.

Kireva, E. y Gabriel, C. (2015). Rhythmic Properties of a Contact Variety: Comparing Read and Semi-spontaneous Speech in Argentinean Porteño Spanis. En E. Delais-Roussarie, M. Avanzi, y S. Herment (Eds.), Prosody and languages in contact. L2 acquisition, attrition, languages in multilingual situations (pp. 149-168). Berlín: Springer. 
Eva Patricia Velásquez Upegui. Entonación de enunciados declarativos en el español hablado en Quer...

Kireva, E. y Gabriel, C. (2016). Intonational convergence in information-seeking yes-no questions: the case of Olivenza Portuguese and Olivenza Spanish. Proceedings of Speech Prosody 2016, 390-394.

Ladd, D. R. (1996). Intonational Phonology. Inglaterra: Cambridge University Press.

López-Bobo, M. J. y Cuevas Alonso, M. (2009). ¿Prosodia norteña o castellana? Aproximación a la entonación del oriente de Cantabría. Estudios de Fonética Experimental, 18, 215-236.

Martín-Butragueño, P. (2004). Configuraciones circunflejas en la entonación del español mexicano. Revista de Filología Española, 84, 347-373.

Martín-Butragueño, P. (2006a). El estudio de la entonación del español de México. En M. Sedano, A. Bolívar, y M. Shiro (Eds.), Haciendo lingüistica. Homenaje a Paola Bentivoglio (pp. 105-126). Caracas: Universidad Central de Venezuela.

Martín-Butragueño, P. (2006b). Proyección sintáctico discursiva de la entonación circunfleja mexicana. En C. Company Company (Ed.), Elespañol en América. Diatopia, diacronía e historiografía. Homenaje a José G. Moreno de Alba en su 65 aniversario (pp. 35-63). Ciudad de México: Universidad Nacional Autónoma de México.

Martín-Butragueño, P. (2011). Estratificación sociolingüística de la entonación circunfleja mexicana. En P. Martín Butragueño (Ed.), Realismo en el análisis de corpus orales. Primer coloquio de cambio y variación lingüistica (pp. 93-121). Ciudad de México: El Colegio de México.

Martín-Butragueño, P. (2014). Historia de dos medidas: contacto entonativo en la Ciudad de México. IV Coloquio Internacional de Cambio y Variación Lingüistica: Contacto Lingüistico. Recuperado de http://generomexico.co lmex.mx/index.php/pedro-martin-butragueno

Martín Butragueño, P. (2016). Inmigración y construcción de la identidad lingüística. Cuadernos AISPI, 8, 145-170.

Martín Butragueño, P. (2019). Aproximación a la entonación del español de la ciudad de Oaxaca, México: hacia una geoprosodia. Moenia, 25, 539-596.

Martín Butragueño, P., Mendoza Vázquez, É. y Orozco, L. (en prensa). Corpus oral del español de México. Ciudad de México: El Colegio de México. Recuperado de https://lef.colmex.mx/corpus_oral_del_espanol_de_mexico.ht $\mathrm{ml}$

Martínez Celdrán, E. y Fernández Planas, A. M. (2003-2020). AMPER. Atlas Multimédia de la Prosódia de l'Espai Románic. Recuperado de http://stel.ub.edu/labfon/amper/cast/index_ampercat.html

Mendoza Vázquez, É. (2014). La impresión de un tono: estudio sociolingüistico de la entonación de Cuapiaxtla, Tlaxcala. (Tesis Doctoral). El Colegio de México. Recuperado de https://repositorio.colmex.mx/concern/theses/5q47r p016?locale $=$ es

Mendoza Vázquez, É. (2019). Entonación de los enunciados aseverativos en el Español de Tuxtla Gutiérrez, Chiapas. Nueva Revista de Filologia Hispánica, 67(1), 41-76.

Montellano Moreno, U. (2017). Características prosódicas del español de Monterrey: enunciados declarativos neutros y enunciados interrogativos absolutos. (Tesis de Licenciatura). México: Escuela Nacional de Antropología e Historia.

Murrieta Bello, L. (2016). Acercamiento al análisis experimental del umbral de percepción entonativa en el español del centro de México. Estudios de Lingüistica Aplicada, 34(63), 34-63.

Orozco, L. (2016). Aproximación a la entonación de enunciados declarativos en Guadalajara. Estudios de Lingüistica Aplicada, 34(63), 13-35. Recuperado de https://ela.enallt.unam.mx/index.php/ela/article/view/635/705

Palancar, E. L. (2009). Gramática y textos del hñöñhö otomi de San Ildefonso Tultepec, Querétaro (Volumen 1). Ciudad de México: Plaza y Valdés.

Pamies Bertrán, A., Fernández Planas, A. M., Martínez Celdrán, E., Ortega Escandell, A. y Amorós Céspedes, M. C. (2002). Umbrales tonales en español peninsular. Actas del II Congreso Nacional de Fonética Experimental, 272-278.

Pierrehumbert, J. B. (1980). The phonetics and phonology of English intonation. Estados Unidos: Massachusetts Institute of Technology. Recuperado de http://www.phon.ox.ac.uk/jpierrehumbert/publications.html

Prieto, P. (2003). Teorias lingüisticas de la entonación. Barcelona: Ariel. 
Prieto, P. y Roseano, P. (s. f). Atlas interactivo de la entonación del español. Barcelona: Universitat Pompeu Fabra.

Prieto, P. y Roseano, P. (2010). Transcription of Intonation of the Spanish Language. Münich: Lincom.

Radillo Enríquez, R. (2011). La entonación de actos de habla asertivos y expresivos en el español de Guadalajara (México): una aproximación sociolingüistica. (Tesis de Maestría). Universidad de Guadalajara. Recuperado de https://www.academia.edu/37496307/Que_en_Guanatos_no_cantamos_sabe.LLa_entonación_de_actos _de_habla_asertivos_y_expresivos_en_el_español_de_Guadalajara_México_una_aproximación_sociolingüíst ica

Rietveld, A. C. y Gussenhoven, C. (1985). On the relation between pitch excursion size and prommence. Journal of Phonetics, 13, 299-308.

Romera, L., Salcioli, V., Fernández-Planas, A. M., Carrera, J. y Román, D. (2008). The Prosody of Simple Sentences in the Spanish of Barcelona, a Spanish-Catalan Bilingual Context. En L. Colantoni y J. Steele (Eds.), Selected Proceedings of the 3rd Conference on Laboratory Approaches to Spanish Phonology (pp. 167-181). Somerville, MA: Cascadilla Proceedings Project.

Sagastuy, P. R. y Fernández Planas, A. M. (2014). La prosodia del español del centro de México en el marco del proyecto AMPER. Estudios de Fonética Experimental, XXIII, 47-94. Recuperado de https://preseea.linguas.net/Metodo logía.aspx

Tovar González, J. (s. f.). Entonación del español rural y urbano. El caso de San Joaquin y Santiago de Querétaro. (Tesis de Licenciatura). Universidad Autónoma de Querétaro.

Utgård, K. (2014). La investigación prosódica del castellano en Guatemala. Situación geográfica, social y lingüística. En Y. Congosto Martín, M. L. Montero Curiel y A. Salvador Plans (Eds.), Fonética experimental, educación superior e investigación (pp. 377-402). Madrid: Arco Libros.

Van Oosterzee, Carlos Fernández Planas, A. M., Romera Barrios, Lourdes Carrera i Sabaté, J., Espuny, J. y Martínez Celdrán, E. (2007). Proyecto AMPER estudio contrastivo de frases interrogativas sin expansión del "tortosí" y del "lleidata". En P. Cano López (Ed.), Actas del VI Congreso de Lingüistica General (pp. 1977-1990). Santiago de Compostela: Arco libros.

\section{Notas}

1 La situación del otomí de San Ildefonso Tultepec es bastante similar a lo que Bermeo (2011) describe para el otomí de Santiago de Mexquititlán, que se encuentra desplazado por el español con alto riesgo de desaparecer.

2 Tovar González (s. f.) realiza una descripción de la entonación rural y urbana en el estado de Querétaro, y compara los municipios de San Joaquín y Santiago de Querétaro.

3 Por ejemplo, en el estudio de Gil Burgoin (2017), se consideraron dos hablantes mujeres por cada ciudad, mientras que en el trabajo de Martín Butragueño (2019), participaron cinco hombres y cuatro mujeres estratificados según la edad.

4 En cuanto a la proximidad con el estado de Querétaro, las descripciones del español de la Ciudad de México son particularmente relevantes.

5 Con relación a la entonación del otomí, se ha dicho que hay un acento entonacional largo y fuerte que se encuentra a nivel de frase (Guerrero Galván, 2015; Palancar, 2009). Sobre la variedad del otomí de Santiago Mexquitlán (en el mismo estado de Querétaro), Hekking y Andrés de Jesús (1984) explican que la oración afirmativa no está marcada mediante un elemento sintáctico o morfológico a diferencia del enunciado interrogativo.

6 Se eligieron las participantes de esta edad debido a que son pocas las personas menores que hablan la lengua en la comunidad, y además, no aprendieron el otomí como lengua materna. Con relación al nivel de estudios, las participantes entrevistadas no cuentan con estudios posteriores a la educación primaria.

7 Este mismo tipo de instrumento se emplea en Prieto y Roseano (2010) para la elicitación de enunciados declarativos de foco amplio como los considerados en el presente estudio. De igual manera, se emplea en proyectos generales como el Corpus Oral del Español de México (COEM) (Martín Butragueño, Mendoza Vázquez y Orozco, en prensa) y el Atlas Interactivo de la Entonación del Español (ATLES) (Prieto y Roseano, s. f.).

8 En el caso de las hablantes bilingües se grabaron los enunciados tanto en español como en otomí. Las versiones en otomí no hacen parte de este análisis dado que esta tarea excede los límites de esta investigación, además, tal descripción no hace parte de los objetivos planteados en este estudio. En el futuro convendría explorar en más detalle la posibilidad de que algunas de las características de la zona se den directamente por ese contacto. Un estudio con un componente 
Eva Patricia Velásquez Upegui. Entonación de enunciados declarativos en el español hablado en Quer...

perceptual (por ejemplo de discriminación entre variedades) también ayudaría a determinar si estos movimientos tonales son percibidos como característicos de la zona de Querétaro (o al menos en algunos de sus hablantes).

9 Las imágenes son una serie de fotografías documentales de retratos a color, con un diafragma abierto sin descontextualizar el entorno de la(s) persona $(s)$ retratada $(s)$.

10 Hualde y Prieto (2015) presentaron modificaciones en el sistema notación para hacerlo común con las distintas lenguas romances (Frota y Prieto, 2015), dados los intereses de esta investigación, se ha decidido mantener el sistema de notación previo. Las diferencias conciernen, esencialmente, al acento tonal ascendente con el pico desplazado de la sílaba postónica que pasó de $\mathrm{L}+>\mathrm{H}^{*}$ a $\mathrm{L}+<\mathrm{H}^{*}$, y las junturas terminales $\mathrm{M} \%$ y $\mathrm{HH} \%$ se han sustituido por $! \mathrm{H} \%$ y $\mathrm{H} \%$, respectivamente.

11 Rietveld y Gussenhoven (1985), con datos del holandés, encontraron que una diferencia de 1.5 st. permite percibir diferencias en la F0.

12 Este resultado indica que ambas formas son producidas por este grupo de hablantes al emitir los enunciados declarativos.

13 Las HB mostraron un mayor número de enunciados conformados por tres acentos tonales en comparación con las HMA y HMQ, mientras que las HMA presentaron más enunciados con un acento tonal, a diferencia de las HB y HMQ que produjeron enunciados con dos acentos tonales.

14 En cuanto al acento nuclear es probable que la entonación en contacto se haya extendido a los demás grupos de hablantes en la región y que se haya adquirido justamente esta variedad en contacto. 